

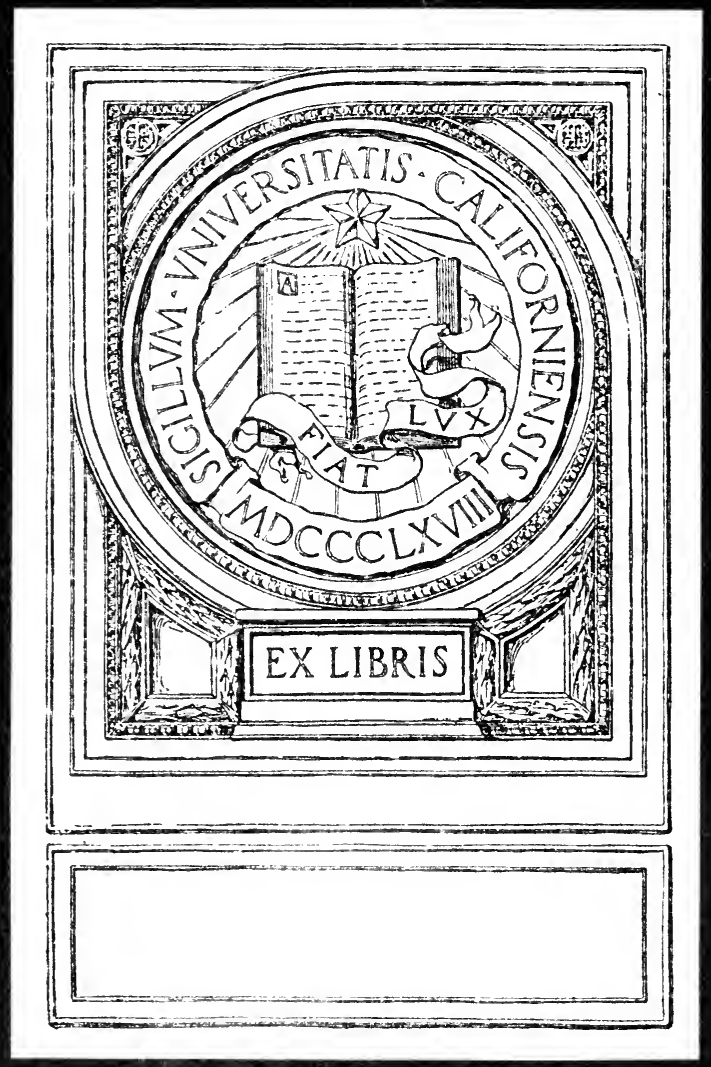




\section{Report of Committee on Concrete and Reinforced Concrete.}

Authorized Reprint from the Copyrighted

Procemdngas of the American Society for Thgting Materials, Phimadelphi, Penna.

Volume XIII, 1913. 


$$
\begin{gathered}
\because \\
\because \\
\hdashline
\end{gathered}
$$




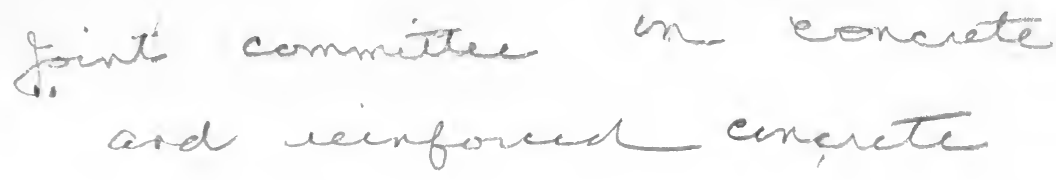

\section{Report of Committee on Concrete and Reinforced Concrete.}

Authorized Reprint from the Copyrighted

Proceedings of the American Society for Testing Materials, Philadelphia, Penna.

Volume XIII, 1913. 


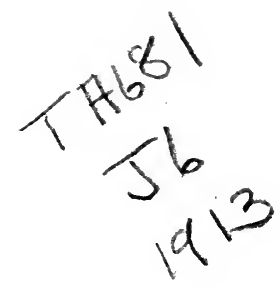

$$
\begin{aligned}
& \because \because \quad \because \because \vdots \vdots \vdots \vdots \vdots \vdots 0
\end{aligned}
$$

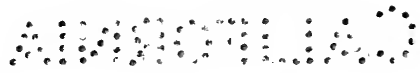


APPENDIX.

\section{REPORT ON CONCRETE AND REINFORCED CONCRETE.}

Revised at the Meeting of the Joint Committee on Concrete and Reinforced Concrete, New York, N. Y., November 20, 1912.

December 1, 1912.

I. INTRODUCTION.

I. Appointment and Work of Committee.

In 1903 and 1904 special committees were appointed by the American Society of Civil Engineers, American Society for Testing Materials, American Railway Engineering and Maintenance of Way Association and the Association of American Portland Cement Manufacturers, for the purpose of investigating current practice and providing definite information concerning the properties of concrete and reinforced concrete and to recommend necessary factors and formulas required in the design of structures in which these materials are used. The history of the appointment of the committees is as follows:

At the annual convention of the American Society of Civil Engineers held at Asheville, N. C., June 11, 1903, the following resolution was adopted:

It is the sense of this meeting that a special committee be appointed to take up the question of concrete and steel concrete, and that such committee cooperate with the American Society for Testing Materials and the American Railway Engineering and Maintenance of Way Association.

Following the adoption of this resolution, a Special Committee on Concrete and Steel Concrete was appointed by the Board of Direction on May 31, 1904. At the Annual Meeting, held January 18, 1905, the title of this special committee was, at 
the request of the Committee, changed to "Special Committee on Concrete and Reinforced Concrete." This Special Committee held its first meeting at Atlantic City, N. J., June 17, 1904, and effected an organization; Mr. C. C. Schneider was appointed Chairman and Mr. J. W. Schaub, Secretary. Mr. Schneider resigned from the Committee on January 3, 1911, and the Board of Direction on January 31, 1911, appointed Mr. J. R. Worcester as Chairman. On the resignation of Mr. J. W. Schaub, Mr. Richard L. Humphrey was appointed Secretary on October 11, 1905.

At the first meeting of the Committee it was decided to cooperate with similar committees which had been appointed by the American Society for Testing Materials and the American Railway Engineering and Maintenance of Way Association through the organization of a Joint Committee on Concrete and Reinforced Concrete.

At the annual meeting of the American Society for Testing Materials held July 1, 1903, at the Delaware Water Gap, the following resolution was unanimously adopted:

That the Executive Committee be requested to consider the desirability of appointing a committee on "Reinforced Concrete," with a view of cooperating with the committees of other societies in the study of the subject.

At the meeting of the Executive Committee of the American Society for Testing Materials, held December 5, 1903, a special committee on "Reinforced Concrete" was appointed.

The American Railway Engineering and Maintenance of Way Association appointed a Committee on Masonry on July 20,1899 , with instructions as a part of its duties to prepare specifications for concrete masonry. A preliminary set of specifications for Portland cement concrete was reported to and adopted by the Association on March 19, 1903. At the meeting held in Chicago on March 17, 1904, the Committee on Masonry was authorized to cooperate with the Special Committee on Concrete and Reinforced Concrete of the American Society of Civil Engineers, and following this action a special sub-committee was apposnted.

At a meeting of the several special committees representing the above mentioned societies, held at Atlantic City, N. J., June 17, 1904, arrangements were completed for collaborating the 
work of these several committees through the formation of the Joint Committee on Concrete and Reinforced Concrete. Mr. C. C. Schneider was elected temporary chairman and Prof. A. N. Talbot, temporary secretary. The proposed plan of action of the special committee of the American Society of Civil Engineers was outlined, involving the appointment of sub-committees on Plan and Scope, on Tests, and on Ways and Means.

The Joint Committee, at its first meeting, invited the Association of American Portland Cement Manufacturers to join in its deliberations through a committee appointed for the purpose.

The Joint Committee at meetings at St. Louis in October, 1904, and at New York in the following January perfected its organization by the adoption of rules and the choice of Mr. C. C. Schneider as Chairman, Mr. Emil Swensson, Vice-Chairman, and Mr. J. W. Schaub, Secretary. Later, on the resignation of Mr. Schaub, Mr. Richard L. Humphrey was chosen Seçretary. Sub-Committees on Plan and Scope, on Tests, and on Ways and Means, were appointed.

The Joint Committee as thus organized, consisted of the following members:

\section{OFFICERS.}

Chairman-C. C. SchNeIDER.

Vice-Chairman-Emil Swensson.

Secretary-RICHARD L. HuMPhrey.

\section{MEMBERS.}

American Society of Civil Engineers (Special Committee on Concrete and Reinforced Concrete):

Greiner, J. E., Consulting Engineer, Baltimore and Ohio Railroad, Baltimore, Md.

Hatt, W. K., Professor of Civil Engineering, Purdue University, Lafayette, Ind.

Hoff, Olaf, Vice-President, Butler Brothers, Hoff and Company, New York, N. Y.

Humphrey, Richard L., Consulting Engineer; Engineer in Charge, Structural Materials Testing Laboratories, U. S. Geological Survey, Philadelphia, $\mathrm{Pa}$.

Lesley, R. W., President, American Cement Company, Philadelphia, $\mathrm{Pa}$.

Schaub, J. W., Consulting Engineer, Chicago, III. 
Schneider, C. C., Consulting Engineer, Philadelphia, Pa.

Swensson, Emil, Consulting Engineer, Pittsburgh, Pa.

Talbot, A. N., Professor of Municipal and Sanitary Engineering, in charge of Theoretical and Applied Mechanics, University of Illinois, Urbana, Ill.

Worcester, J. R., Consulting Engineer, Boston, Mass.

American Society for Testing Materials (Committee on Reinforced Concrete):

Fuller, William B., Consulting Engineer, New York, N. Y.

Heidenreich, E. Lee, Consulting Engineer, New York, N. Y.

Humphrey, Richard L., Consulting Engineer; Engineer in Charge, Structural Materials Testing Laboratories, U. S. Geological Survey, Philadelphia, Pa.

Johnson, Albert L., Consulting Engineer, St. Louis, Mo.

Lanza, Gaetano, Professor of Theoretical and Applied Mechanics, Massachusetts Institute of Technology, Boston, Mass.

Lasley, R. W., President, American Cement Company, Philadelphia, $\mathrm{Pa}$.

Marhurg, Edgar, Professor of Civil Engineering, University of Pennsylvania, Philadelphia, Pa.

Mills, Charles M., Principal Assistant Engineer, Philadelphia Rapid Transit Company, Philadelphia, Pa.

Moisseiff, Leon S., Engineer of Design, Department of Bridges, New York, N. Y.

Quimby, Henry H., Assistant, Engineer of Bridges, Bureau of Surveys, Philadelphia, Pa.

Taylor, W. P., Engineer in Charge of Testing Laboratory, Philadelphia, Pa.

Thompson, Sanford E., Consulting Engineer, Newton Highlands, Mass.

Turneaure, F. E., Dean of College of Mechanics and Engineering, University of Wisconsin, Madison, Wis.

Wagner, Samuel Tobias, Assistant Engineer, Philadelphia and Reading Railroad, Philadelphia, Pa.

Webster, George S., Chief Engineer, Bureau of Surveys, Philadelphia, $\mathrm{Pa}$.

American Railway Engineering Association (Sub-Committee on Reinforced Concrete):

Beckwith, Frank, Engineer of Bridges and Structures, Lake Shore and Michigan Southern Railroad, Cleveland, Ohio.

Boynton, C. W., Inspecting Engineer, Cement Department, Illinois Steel Company, Chicago, Ill.

Cunningham, A. O., Chief Engineer, Wabash Railroad, St. Louis, Mo.

Scribner, Gilbert H., Jr., Contracting Engineer, Chicago, Ill.

Swain, George F., Professor of Civil Engineering, Massachusetts Institute of Technology, Boston, Mass. 
Association of American Portland Cement Manufacturers (Committee on Concrete and Steel Concrete):

Fraser, Norman D., President, Chicago Portland Cement Company, Chicago, Ill.

Griffiths, R. E., Vice-President, American Cement Company, Philadelphia, Pa.

Hagar, Edward M., Manager, Cement Department, Illinois Steel Company, Chicago, Ill.

Newberry, Spencer B., Manager, Sandusky Portland Cement Company, Sandusky, Obio.

Since organization the following changes have occurred in the personnel of the Joint Committee:

J. W. Schaub, died March 30, 1909.

C C. Schneider, resigned January 3, 1911.

Ernest R. Ackerman, resigned.

T. J. Brady, resigned.

Frank Beckwith, resigned.

A. O. Cunningham, resigned.

George F. Swain, resigned.

The following representatives of the American Railway Engineering Association have since been appointed:

Thompson, F. L., Engineer of Bridges and Buildings, Illinois Central Railroad, Chicago, Ill.

Alternates:

Hotchkiss, L. J., Assistant Bridge Engineer, Chicago, Burlington and Quincy Railroad, Chicago, Ill.

Prior, J. H., Assistant Engineer, Chicago, Milwaukee and St. Paul Railway, Chicago, Ill.

Schall, F. E., Bridge Engineer, Lehigh Valley Railroad, South Bethlehem, $\mathrm{Pa}$.

Tuthill, Job, Assistant Engineer. Cincinnati, Hamilton and Dayton Railway, Cincinnati, Ohio.

At a meeting of the Joint Committee held at Atlantic City, N. J., June 30, 1911, Mr. J. R. Worcester was elected chairman. Meetings of the Joint Committee have been held as follows:

June 17, 1904, at Atlantic City, N. J.

Oct. 4, 5, 6, 1904, at St. Louis, Mo.

Jan. 17, 1905, at New York, N. Y.

June 21, 1905, at Cleveland, Ohio.

June 30, 1905, at Atlantic City, N. J.

Oct. 11, 1905, at New York, N. Y. 
Dec. 14, 1905, at New York, N. Y. June 21, 1906, at Atlantic City, N. J. Dec. 13, 1906, at New York, N. Y. Jan. 15, 1907, at New York, N. Y. March 7, 1907, at New York, N. Y. March 18, 1907 at Chicago, Ill.

June 21, 22, 1907, at Atlantic City, N. J.

Dec. 10, 1907, at New York, N. Y. Oct. 27, 28, 1908, at New York, N. Y. Dec. 9, 10, 11, 1908, at Philadelphia, Pa. June 30, 1911, at Atlantic City, N. J. Nov. 20, 1912, at New York, N. Y.

At the meeting of the Joint Committee at St. Louis in October, 1904, it was determined to arrange tests at such technological institutions as were provided with the requisite facilities and were willing to cooperate, the Committee, through its Sub-Committee on Ways and Means, to provide materials, and through its Sub-Committee on Tests, to consult as to lines of testing and to advise as to methods. The following ten institutions, Case School of Applied Science, Columbia University, Cornell University, University of Illinois, State University of Iowa, Massachusetts Institute of Technology, University of Minnesota, Ohio State University, Purdue University and University of Wisconsin, undertook a preliminary series of tests and carried them through, in due time reporting their results to the Committee.

Through the inability of the Committee to do as much as it had hoped by way of furnishing uniform materials for these tests and exercising a proper supervision, the results were not as serviceable to the Committee as they would have been if the full plans had been carefully carried out; but much important information was received in this manner, and the Committee desires to express its gratitude to the professors and students who so kindly assisted in this work.

The results were collated and edited by the Secretary of the Committee at the Structural Materials Testing Laboratories of the U. S. Geological Survey, St. Louis, and the results in typewritten form were circulated among the members of the Committee. It was hoped that they might be published by the Geological Survey as a Bulletin, but in that the Committee was disappointed, though some of the results have been published in bulletins and papers issued by their authors. 
In June, 1905, the U. S. Geological Survey proposed to cooperate with the Joint Committee to the extent of placing the tests made at the St. Louis Laboratory at the service of the Committee and allowing the Committee the privilege of advising as to what tests of concrete and reinforced concrete should be conducted there. This cooperation was welcomed by the Committee and was brought about by the fact that the Secretary of the Committee, who was also the chairman of the sub-committee on tests; was in charge of the St. Louis Laboratory.

During the five years in which the investigations of structural materials were in progress under the direction of the U. S. Geological Survey, a large amount of data relating to concrete and reinforced concrete was obtained. These investigations have included the survey of the constituent materials of concrete such as sands, gravels and crushed stone, in the various parts of the United States, covering their strength as mortars or concretes in various consistencies and proportions.

A number of series of tests of plain and reinforced concrete beams were made, covering the influence of character of aggregates, proportions and age, percentage of reinforcement, the effect of the variation in span relative to the depth, methods of anchorage of the reinforcement, etc., upon strength. A study was made of the effect of the personal equation in tests of beams, made by three construction companies operating in St. Louis and by the employees of the testing laboratory. Tests covering bond, shear, compressive strength, and weight per cubic foot, for various classes of aggregates, were made.

Among other investigations were tests of reinforced concrete slabs, $12 \mathrm{ft}$. span supported at two and four edges, of strength and other properties of cement hollow building blocks, of the permeability of cement mortars and concretes, value of various waterproofing and dampproofing preparations, effect of alkali and sea water on cement mortars and concretes, the fire-resistive properties of concrete and other structural materials, and these have been made and published, in part.

The collation and study of the data obtained were seriously handicapped through lack of funds available for this purpose, the large part of the appropriation being devoted to work urgently required by the various Government Bureaus. Of the 
annual Government appropriation of $\$ 100,000$ there was never available more than $\$ 15,000$ per annum for investigation of concrete and reinforced concrete, and several years the amount did not exceed $\$ 5,000$ a year. None of this was available for the publication of results, and the allotment from the funds provided for all Government printing was wholly inadequate for the purpose.

On June 30, 1910, Congress transferred this work to the Bureau of Standards together with the data collected. It is understood that arrangements have been made by which the data of the tests will be published as rapidly as conditions permit.

The Committee has had the benefit of the results of investigations by a number of laboratories some of which were under the direct supervision of its members. The extent and varied character of the tests, and their interpretation by those in charge, made them of especial value to the Committee.

The Committee also has had the advantage of investigations made in foreign laboratories.

At a meeting of the Joint Committee at Atlantic City, June 30,1905 , it was decided to divide among its members the work of collating and digesting the results of all available tests on concrete and reinforced concrete, and in pursuance of this resolution, sub-committees were appointed on the following subjects:

Historical.

Aggregates, Proportions and Mixing.

Physical Characteristics, Waterproofing, etc.

Strength and Elastic Properties.

Simple Reinforced Concrete Beams.

T-Beams, Floor Slabs, etc.

Columns and Piles.

Fire-resistive Qualities.

Failures of Concrete Structures.

Arches.

A large amount of work was done by these sub-committees and extensive reports were submitted by most of them. These reports were typewritten in manifold and circulated among the members of the Joint Committee, and were of great value to the Committee in arriving at its conclusions. 
The Sub-Committee on Ways and Means raised by subscription about $\$ 8,000$ which was used for preliminary investigations and expenses incident to printing its report and carrying on work of the Committee. The Committee desires to express its appreciation for contributions and for donations of materials.

Even with this support the field of activity of the Committee has been limited in scope and it has been unable to undertake investigations of its own.

In 1908 the Committee began the preparation of the Progress Report which was submitted to the Society in January, 1909. A preliminary outline was prepared by the Secretary and submitted to the Committee in October. On October 27, a meeting of the Joint Committee was held at New York, at which the report was discussed paragraph by paragraph and chapters were referred to sub-committees and carefully revised during the following three weeks. The whole, as thus amended and revised, was'again submitted in print to a full meeting held in Philadelphia, December 9, 10 and 11, and again was gone over in great detail. As a result of those two meetings, a considerable amount of matter which it was at first intended to include was omitted on account of slight disagreements as to its form, and lack of time to work it into satisfactory shape, and to this fact may be attributed some of the criticisms which have been elicited. It is hoped, in this report, to avoid these objections.

In the spring of 1911 the work of revising the 1909 progress report was taken up and a number of meetings were held. The discussions submitted to the American Society of Civil Engineers and subsequent papers relating to the same subject were carefully considered, and differences of opinion between members of the Committee were threshed out.

Through the cooperation of the societies represented on the Joint Committee the report was again put in type and the necessary editions were printed for the use of the members of the Committee, the last bearing the date of August 1, 1911. In the form thus reached the report remained until November 20, 1912, when the Committee again met in New York and gave a final review needed to bring it into the shape in which it is now presented. 


\section{HISTORICAL SKETCH OF USE OF CONCRETE AND REINFORCED CONCRETE.}

In considering the history of concrete and reinforced concrete, a distinction should be made between the two. The use of concrete extends back to long before the Christian era-while on the other hand the art of reinforced concrete is in its infancy.

The use of concrete by the ancient Romans was due to the discovery of the fact that volcanic ash or puzzolan, when mixed with slaked lime, made a cement possessing hydraulic properties. The durability of this work of the Romans was due largely to favorable climatic conditions and the character of the cement used.

From the downfall of the Roman Empire to the last half of the eighteenth century the manufacture of cement seems to have been discontinued. The Roman cement mortars and concretes surviving the ravages of the elements became so hard that the cement acquired a reputation that led the early experimenters of the eighteenth century to seek to recover this supposed lost Roman art. Evidently no concrete was used during this period, for the necessity of simultaneous induration in the interior and exterior of the mass prevents the use of lime alone in concrete and requires the use of some material having hydraulic qualities. This fact limited the use of concrete to regions where hydraulic limes and cements were to be found.

In 1756 Smeaton discovered that an argillaceous limestone produced a lime that would set and harden under water, but no immediate appreciation of this knowledge appears to have resulted.

Natural cement was first manufactured by Parker in 1795 as a result of an attempt to equal or excel Roman cement, and in 1796 he took out an English patent. Natural cement was first produced in America in 1818 and for a long time was the principal cement used. With the introduction of Portland cement, and the reduction in the cost of manufacture, there has been a gradual substitution of Portland for natural cement. The production of natural cement reached a maximum of nearly $10,000,000$ barrels in 1899 and has since gradually decreased to about 900,000 barrels in 1911 .

The art of manufacturing Portland cement was discovered in 1811 by Joseph Aspdin and patented by him in 1824 . He 
called this cement "Portland" by reason of its resemblance to a building stone obtained from the Isle of Portland, off the coast of England. I Up to 1850 very little progress was made in the manufacture of this cement in England. Since 1855, however, the increase in the production in Europe has been steady, and its superiority has led to a gradually increasing use in such structures as require concrete in mass, as foundations, fortifications, seawalls, docks, locks, etc. While Portland cement was first manufactured in 1824 and was produced in 1871 by David O. Saylor at Coplay, Pa., and by Thomas Millen at South Bend, Ind., it was not until the early eighties that it was manufactured to any extent in America. From that time on the production has rapidly increased, reaching the enormous total of nearly $80,000,000$ barrels in 1911. This increase in production has been largely stimulated by the reduction in cost of Portland cement through the perfection of the American methods, the introduction of reinforced concrete and the extensive use of cement during the last few years.

In 1850 Joseph Gibbs obtained a British patent for casting solid walls in wooden molds, and in 1897 C. W. Stevens obtained a patent for making artificial cast stone with concrete. It is not clear, however, that these inventors were the first to use the material in a similar way.

The origin of the idea of increasing the load-carrying capacity of concrete by reinforcing it with metal embedded in it is generally attributed to Joseph Monier, a French gardener, who used a wire frame or skeleton embedded in concrete in the construction of flower pots, tubs and tanks in 1867, and for which he obtained the first patent of the kind in the same year. This was not the first use of the material, however, as Lambot constructed a boat of reinforced concrete in 1850 which was exhibited at the Paris Exposition in 1853. He took out an English patent in 1855 .

In France in 1861, Francois Coignet applied the principles of reinforced concrete in the construction of beams, arches, pipes, etc., and with Monier exhibited some of their work at the Paris Exposition in 1867. Coignet also took out an English patent in 1855. In England in 1854, W. B. Wilkinson took out a patent for a reinforced concrete floor. In America, Ernest L. Ransome 
used metal in combination with concrete as early as 1874, and W. E. Ward erected, in 1875, at Port Chester, New York, a house built entirely of reinforced concrete.

Monier, while not the first to apply it, obtained the first patents for reinforced concrete, the German and American rights of which he disposed of to G. A. Wayss and Company in 1880. Wayss and J. Bauschinger shortly after began the tests on this material which were published in 1887.

Thaddeus Hyatt, an American engineer, employed David Kirkaldy of London to make the experiments on reinforced concrete which Hyatt published in 1877. The theories of Hyatt were applied in a practical way to building construction in 1877 by H. P. Jackson of San Francisco.

In America, Ransome, between 1874 and 1884, constantly increased his application of metal reinforcement consisting of old wire rope and hoop iron, gradually realizing the necessity for using it with a greater regard for its proper position in the mass, and in 1884 took out the first patent for a deformed bar. Prior to this reinforced concrete was used but little in the United States. Ransome built his first important structure in 1890, the Leland Stanford Jr. Museum Building, $312 \mathrm{ft}$. long, two stories high with basement, the walls and floors of which were of reinforced concrete. Since 1891, when the first slabs of reinforced concrete were used in America, the development has been rapid.

The introduction of this form of construction proceeded more slowly in Europe and between 1891 and 1894 Moeller in Germany, Wünsch and Emperger in Hungary, Melan in Austria and Hennebique in France were pioneers in its development. Hennebique built reinforced concrete slabs as early as 1879 but did not patent his system of construction until 1892.

The first published method of computation was by Koenen and Wayss in 1886. Subsequent theories have been advanced by de Mazas, Neuman, Melan, Coignet, de Tedesco, Von Thullie, Ostenfeld, Sanders, Spitzer, Lutken, Ritter, Hatt, "Talbot, Turneaure and others. As early as 1884 Ransome worked out methods of calculation independent of other investigators, and in 1899 Considére published his important series of tests from which he deduced his methods of calculation. 
During the last ten years the earlier theories have been somewhat modified as experience has been gained, and as the fund of experimental knowledge has accumulated. The trend of the modifications has been towards greater harmony in methods of calculation. Some of the earlier assumptions have been proved fallacious and generally abandoned. On the other hand, some of the refinements of calculation, though known to be in accordance with facts, have, by general consent, been discarded, as they do not affect the design materially or are taken into account by a modification of the constants. Among these are the value of the concrete in the tension side of a beam, and the lack of a uniform modulus of elasticity in compression of concrete under widely varying stress. The earlier theories did not deal with the diagonal tension under shearing stresses. This has been found to be a most important consideration and much attention has been paid to it in recent years. In spite of the study which has already been given it, however, there is still much to learn in this direction. The action of various forms of reinforcement in columns has received much consideration, and there is still a wide difference of opinion as to the efficacy of some forms of column reinforcement. Many experiments have been made in this branch of the subject, and practice appears to be gradually converging towards greater uniformity.

In the preparation of this historical sketch the Committee has endeavored to verify the facts and has received the cooperation of H. Kempton Dyson, Secretary of the Concrete Institute of England, Alfred Huser, President Deutscher Beton-Verein, C. von Bach, Otto Leube, of Germany, Karl Naehr, of Austria, Joseph Schustler, of Hungary, and H. I. Hannover, of Denmark, to whom the Committee wishes to acknowledge its appreciation and thanks.

\section{AUTHORITIES ON WHICH RECOMMENDATIONS ARE BASED.}

It has been suggested that a report such as this should include all the data upon which conclusions are based. The impracticability of this may not be realized by those who are not familiar with the enormous quantity of matter involved. There are, however, reasons other than the magnitude of the task which tend to show that full publication is not advisable. One of 
these is that most of the experimental results have already appeared in print and are now available, and a reprint of them would be of no great advantage to anyone. Where originally printed they are frequently accompanied with comments and deductions by their author, which are of great value as such but could scarcely be copied by the Committee. Another reason against publication is that in the large part of the experimental work consulted it has been found that certain vitally important information, either with regard to the materials, the way in which they are manipulated or as to the precise results reached, are lacking. The omission of measurements of deformations, of course, frequently renders results of little value. While such tests may have some use on account of particular facts developed, a large part may be useless, and consequently unsuitable for publication. The difficulty of separating the valuable from the valueless would be almost insurmountable.

It may not be improper, however, to append the following list of authors and references, as comprising a considerable part of the most important published material upon the subject under consideration:

C. v. BACH.—Compressive Tests: Deutsche Bauzeitung, 1905, 68 (No. 17). Mitteilungen über Forschungsarbeiten, Nos. 22, $29,39,45-47,72-74$.

E. CAndoot.-Cements and Mortars: Ciments et Chaux Hydrauliques; 1898, p. 446, 447.

Howard A. Carson.-Plain and Reinforced Concrete Beams: Boston Transit Commission, 10th Annual Report, 1904, Appendix G.

A. Considére.-Reinforced Beams and Columns: Comptes Rendus de l'Academie des Sciences, CXXVII, p. 992; CXXIX, p. 467; CXXXV, 8 Sept., 1902; CXL, 30 June, 1905.

F. v. EMPerger.-Forschungsarbeiten auf dem Gebiete des Eisenbetons. No. 8.

R. Feret.-Sur la compacité des mortiers hydrauliques; Annales des Ponts et Chaussées, 1892, II. Composition, Various Tests of Reinforcing: Etude Experimentale du ciment armé, 1906. William B. Fuller and Sanford E. Thompson.-Composition and Density: Transactions American Society of Civil Engineers, Vol. LIX, 1907, p. 67. 
William K. Hatt.-Reinforced Concrete Beams: Proceedings American Society for Testing Materials, Vol. II, 1902, p. 161; Journal Western Society of Engineers, June, 1904.

JAmes E. Howard.-Watertown Arsenal Tests of Cubes and Reinforced Columns: Tests of Metals, U. S. A., 1897, 1898, 1899, 1903, 1905, and 1906; Proceedings American Society for Testing Materials, Vol. VI, 1906, p. 346.

Richard L. Humphrey.-St. Louis Laboratory Tests of Aggregates, Beams, Prisms, Fire Resistance: U. S. Geological Survey, Bulletins 324, 329, 331, 344, 370, and Bureau of Standards, Technologic Paper 2.

George A. Kimball.-Compressive Tests of Cubes: Tests of Metals, U. S. A., 1899.

Gaetano Lanza.-Reinforced Columns and Beams: Transactions American Society of Civil Engineers, Vol. L, 1903, p. 483; Proceedings American Society for Testing Materials, Vol VI, 1906, p. 416.

Elmer J. McCaustland.-Plain and Reinforced Columns: Engineering News, Vol. LIII, p. 614, June 15, 1905.

Edgar Marburg.-Reinforced Concrete Beams and Piers: Proceedings American Society for Testing Materials, Vol. IV, 1904, p. 508; Vol. IX, 1909, p. 509.

E. MöRsCH.-Der Eisenbetonbau.

Charles L. Norton.-Fireproofing, Protection of Steel by Concrete:

Boston Insurance Engineering Experiment Station Reports, IV and IX.

Logan W. Page.-Properties of Oil-mixed Portland Cement Mortar and Concrete: Transactions American Society of Civil Engineers, Vol. LXXIV, 1911, p. 255.

George W. Rafter.-Consistency and Proportions: Tests of Metals, U. S. A., 1898.

M. Rudeloff.-Versuche mit Eisenbeton-Säulen, Beton and Eisen, March 9, 1911.

F. SchüLE.-Resultate der Untersuchung von Armierten Beton. Zürich, 1906.

Arthur N. Talbot.-Prisms, Beams, Columns: Proceedings American Society for Testing Materials, Vol. IV, 1904, p. 476; Vol. VII, 1907, p. 382. University of Illinois Bulletins, Nos. $1,4,8,10,12,14,20,22,28,29$. 
Arthur N. Talbot and Arthur R. Lord.-Concrete as Reinforcement for Structural Steel Columns: University of Illinois Bulletin, No. 56.

Sanford E. Thompson.-Permeability and Consistency: Proceedings American Society for Testing Materials, Vol. VI, 1906, p. 358, and Vol. VIII, 1908, p. 500.

Frederick E. Turneaure.-Beams, Columns: Proceedings American Society for Testing Materials, Vol. IV, 1904, p. 498.

U. S. Geological Survey Tests.-Tests of High-Pressure Steam on Concrete and of Dampproofing and Waterproofing Compounds: under direction of Richard L. Humphrey. Published by Bureau of Standards, Technologic Papers 3 and 5. John L. Van Ornum.-Fatigue in Reinforced Beams: Transactions American Society of Civil Engineers, Vol. LVIII, 1907, p. 294.

Morton O. Withey.-Beams, Columns: Bulletins University of Wisconsin, Vol. IV, Nos. 1, 2; Vol. V, Nos. 2, 5.

IrA H. Woolson.-Effect of Heat: Proceedings American Society for Testing Materials, Vol. VI, 1906, p. 433, and Vol. VII, 1907, p. 404.

Recommendations of British Reinforced Concrete Committee, 1907, 1911.

Regulations of Prussian Government, 1904, 1907.

Rules of French Government, 1907.

Recommendations of Swiss Society of Engineers and Architects, 1909.

Rules of the Austrian Ministry of the Interior, 1908, 1911.

In addition to the authorities above quoted, the Committee desires to acknowledge with thanks the discussions of its progress report which have appeared from time to time and to say that all the points brought out therein have been carefully weighed.

\section{CHARACTER OF REPORT PRESENTED.}

At the time of the appointment of the Committee, in 1904, there existed a great diversity of opinion in America as to methods of design, safe allowable working stresses and methods of proportioning, handling, etc. A great deal of experimental 
work had been done, but there was need of a clearing house through which results could be compared and divergent views harmonized. During the interval between the appointment of the Committee and the preparation of its first progress report, rapid advance was made in the art of concrete construction aided by the results of the investigations and the experience acquired by constructors. This report, which was submitted in 1909, attempted to embody recommendations for safe methods of construction and design in accordance with the best practice of the day. It would have been impossible for such a report to meet with the approval of all, and the Committee is well satisfied that its most vital recommendations have met with quite general acceptance by the engineers of the country.

Since the appearance of the first progress report many experiments have been conducted by some of the technical institutions and by private and corporate interests, and through these and through longer experience in construction by its members and others, the Committee is now able to make some perfecting modifications of its former report and to add some entirely new material. The time therefore seems opportune for presenting this second report bringing the work up to date.

The Committee would point out that while the report deals with every kind of stress to which concrete is subjected and includes all ordinary conditions of proportioning and handling, it does not go into all types of construction or all the applications to which concrete and reinforced concrete may be put.

It is not to be assumed that the Committee in presenting this report wishes to imply that further improvements are not possible. A careful reading will disclose many points on which the present deductions are regarded as only tentative, but it has been the aim of the Committee to cover as fully as possible recommendations based on the present state of the art.

This report is what the word implies and nothing more; it is not a "specification," but may be used as a basis for specifications.

The use of concrete and reinforced concrete involves the exercise of good judgment to a greater degree than for any other building material.

Rules can not produce or supersede judgment; on the con- 
trary, judgment should control the interpretation and application of rules.

\section{Adaptability of Concrete and Reinforced Concrete.}

The adaptability of concrete and reinforced concrete for engineering structures, or parts thereof, is now so well established that they may be considered the recognized materials of construction. They have proved satisfactory materials, when properly used, for those purposes for which their qualities make them particularly suitable.

\section{USES.}

Concrete is a material of very low tensile strength and capable of sustaining but very small tensile deformations without rupture; 'its value as a structural material depends chiefly upon its durability, its fire-resistive qualities, its strength in compression, its relatively low cost, and its adaptability to placing, especially where space is cramped or limited.| Its strength increases generally with age.

Concrete is well adapted for structures in which the principal stresses are compressive, such as foundations, dams, retaining and other walls, tunnels, piers, abutments, short columns and, in many cases, arches. In the design of massive concrete, the tensile strength of the material in resisting principal stresses must generally be neglected.

$\checkmark$ By the use of metal reinforcement to resist the principal tensile stresses, concrete becomes available for general use in a great variety of structures and structural forms. This combination of concrete and metal is particularly advartageous in the beam, where both compression and tension exist; it is also advantageous in the column where the main stresses are compressive, but where cross-bending may exist. In structures resisting lateral forces it possesses advantages over plain concrete in that it may be designed so as to utilize more fully the strength rather than the weight of the material. Metal reinforcement may also be of value in distributing cracks due to shrinkage and temperature changes. 


\section{PRECAUTIONS.}

Failures of reinforced concrete structures are usually due to any one or a combination of the following causes: defective design, poor material, faulty execution, and premature removal of forms.

The defects in a design may be many and various. The computations and assumptions on which they were based may be faulty and contrary to the established principles of statistics and mechanics; the unit stresses used may be excessive, or the details of the design defective.

Articulated concrete structures designed in imitation of steel trusses may be mentioned as illustrating a questionable use of reinforced concrete, and such structures are not recommended.

Poor material is sometimes used for the concrete, as well as for the reinforcement. The use of poor aggregates, especially sand, which have not been tested is a common source of defect. Inferior concrete is frequently due also to lack of experience on the part of the contractor and his superintendents, or to the absence of proper supervision.

An unsuitable quality of metal for reinforcement is sometimes prescribed in specifications, for the purpose of reducing the cost. For steel structures, a high grade of material is specified, while the steel used for reinforcing concrete is sometimes made of unsuitable, brittle material.

Faulty execution, careless workmanship and too early removal of forms may generally be attributed to unintelligent or insufficient supervision.

\section{RESPONSIBILITY AND SUPERVISION.}

The design of reinforced concrete structures should receive at least the same careful consideration as those of steel, and only engineers with sufficient experience and good judgment should be intrusted with such work.

The computations should include all minor details, which are sometimes of the utmost importance. The design should show clearly the size and position of the reinforcement and should provide for proper connection between the component parts, so that they cannot be displaced. As the connection between 
reinforced concrete members are frequently a source of weakness, the design should include a detailed study of such connections, accompanied by computations to prove their strength.

While other engineering structures on the safety of which human lives depend are generally designed by engineers employed by the owner, and the contracts let on the engineer's design and specifications, in accordance with legitimate practice, reinforced concrete structures frequently are designed by contractors or by engineers commercially interested, and the contract let for a lump sum.

The construction of buildings in large cities is regulated by ordinances or building laws, and the work is inspected by municipal authorities. For reinforced concrete work, however, the limited supervision which municipal inspectors are able to give is not sufficient. Therefore, means for more adequate supervision and inspection should be provided.

The execution of the work should not be separated from the design, as intelligent supervision and successful execution can be expected only when both functions are combined. The engineer who prepares the design and specifications should have, therefore, the supervision of the execution of the work.

The Committee recommends the following rules for structures of reinforced concrete for the purpose of fixing the responsibility and providing for adequate supervision during construction:

(a) Before work is commenced, complete plans shall be prepared, accompanied by specifications, stress computations, and descriptions showing the general arrangement and all details. The plans shall show the size, length, dimensions for points of bending, and exact position of all reinforcement, including stirrups, ties, hooping and splicing. The computations shall give the loads assumed separately, such as dead and live loads, wind and impact, if any, and the resulting stresses.

(b) The specifications shall state the qualities of the materials to be used for making the concrete, and the manner in which they are to be proportioned.

(c) The strength which the concrete is expected to attain after a definite period shall be stated in the specifications.

(d) The drawings and specifications shall be signed by the engineer and the contractor. 
(e) Plans and specifications for all public structures should be approved by a legally authorized state or city official, and copies of such plans and specifications placed on file in his office.

$(f)$ The approval of plans and specifications by other authorities shall not relieve the engineer nor the contractor of responsibility.

(g) Inspection during construction shall be made by competent inspectors employed by and under the supervision of the engineer, and shall cover the following:

1. The materials.

2. The correct construction and erection of the forms and the supports.

3. The sizes, shapes and arrangement of the reinforcement.

4. The proportioning, mixing and placing of the concrete.

5. The strength of the concrete by tests of standard test pieces made on the work.

6. Whether the concrete is sufficiently hardened before the forms and supports are removed.

7. Prevention of injury to any part of the structure by and after the removal of the forms.

8. Comparison of dimensions of all parts of the finished structure with the plans.

(h) Load tests on portions of the finished structure shall be made where there is reasonable suspicion that the work has not been properly performed, or that, through influences of some kind, the strength has been impaired. Loading shall be carried to such a point that one and three quarters times the calculated working stresses in critical parts are reached, and such loads shall cause no injurious permanent deformations. Load tests shall not be made until after 60 days of hardening.

\section{DESTRUCTIVE AGENCIES.}

(a) Corrosion of Metal Reinforcement.-Tests and experience indicate that steel sufficiently embedded in good concrete is well protected against corrosion no matter whether located above or below water level. It is recommended that such protection 
- be not less than $1 \mathrm{in}$. in thickness. If the concrete is porous so as to be readily permeable by water, as when the concrete is laid with a very dry consistency, the metal may corrode on account of the presence of moisture and air.

(b) Electrolysis.-The most recent experimental data available on this subject seem to show that while reinforced concrete structures may, under certain conditions, be injured by the flow of electric current in either direction between the reinforcing material and the concrete, such injury is generally to be expected only where voltages are considerably higher than those which usually occur in concrete structures in practice. If the iron be positive, trouble may manifest itself by corrosion of the iron accompanied by cracking of the concrete, and, if the iron be negative, there may be a softening of the concrete near the surface of the iron, resulting in a destruction of the bond. The former, or anode effect, decreases much more rapidly than the voltage, and almost if not quite disappears at voltages that are most likely to be encountered in practice. The cathode effect, on the other hand, takes place even on very low voltages, and is therefore more important from a practical standpoint than that of the anode.

Structures containing salt or calcium chloride, even in very small quantities, are very much more susceptible to the effects of electric currents than normal concrete, both the anode and cathode effects progressing much more rapidly in the presence of chlorine.

There is great weight of evidence to show that normal reinforced concrete structures free from salt are in very little danger under most practical conditions, while non-reinforced concrete structures are practically immune from electrolysis troubles.

The results of experiments now in progress may yield more conclusive information on the subject.

(c) Sea .Water.-The data available concerning the effect of sea water on concrete or reinforced concrete are limited and inconclusive. Sea walls out of the range of frost action have been standing for many years without apparent injury. In many harbors where the water is brackish, through rivers discharging into them, serious disintegration has taken place. This has occurred chiefly between low and high tide levels and is due, evidently, in part to frost. Chemical action also appears to be indicated by the softening of the mortar. To effect the best 
resistance to sea water, the concrete must be proportioned, mixed and placed so as to prevent the penetration of sea water into the mass or through the joints. The cement should be of such chemical composition as will best resist the action of sea water; the aggregates should be carefully selected, graded and proportioned with the cement so as to secure the maximum possible density; the concrete should be thoroughly mixed; the joints between old and new work should be made watertight; and the concrete should be kept from exposure to sea water until it is thoroughly hard and impervious.

(d) Acids.-Concrete of first class quality thoroughly hardened is affected appreciably only by strong acids which seriously injure other materials. A substance like manure is injurious to green concrete, but.after the concrete has hardened thoroughly it resists the action of such acid satisfactorily.

(e) Oils.-When concrete is properly made and the surface carefully finished and hardened, it resists the action of such mineral oils as petroleum and ordinary engine oils. Oils which contain fatty acids produce injurious effects, forming compounds with the lime which result in a disintegration of the concrete in contact with them.

(f) Alkalies.-The action of alkalies on concrete is problematical. In the reclamation of arid land where the soil is heavily charged with alkaline salts it has been found that concrete, stone, brick, iron and other materials are injured under certain conditions. It would seem that at the level of the ground water in an extremely dry atmosphere such structures are disintegrated, through the rapid crystallization of the alkaline salts, resulting from the alternate wetting and drying of the surface. Such destructive action can be prevented by the use of a protective coating and is minimized by securing a dense concrete.

\section{Materials.}

A knowledge of the properties of the materials entering into concrete and reinforced concrete is the first essential. The importance of the quality of the materials used cannot be overestimated, and not only the cement but also the aggregates should be subject to such definite requirements and tests as will insure concrete of the desired quality. 


\section{CEMENT.}

There are available for construction purposes Portland, Natural and Puzzolan or Slag cements. Only Portland cement is suitable for reinforced concrete.

(a) Portland Cement is the finely pulverized product resulting from the calcination to incipient fusion of an intimate mixture of properly proportioned argillaceous and calcareous materials. It has a definite chemical composition varying within comparatively narrow limits.

Portland cement should be used in reinforced concrete construction and any construction that will be subject to shocks or vibrations or stresses other than direct compression.

(b) Natural Cement is the finely pulverized product resulting from the calcination of an argillaceous limestone at a temperature only sufficient to drive off the carbonic acid gas. Although the limestone must have a certain composition, this composition may vary within much wider limits than in the case of Portland cement. Natural cement does not develop its strength as quickly nor is it as uniform in composition as Portland cement.

Natural cement may be used in massive masonry where weight rather than strength is the essential feature.

Where economy is the governing factor a comparison may be made between the use of natural cement and a leaner mixture of Portland cement that will develop the same strength.

(c) Puzzolan or Slag Cement is the finely pulverized product resulting from grinding a mechanical mixture of granulated basic blast furnace slag and hydrated lime.

Puzzolan cement is not nearly as strong, uniform or reliable as Portland or natural cement, is not used extensively and never in important work; it should be used only for foundation work underground where it is not exposed to air or running water.

(d) Specifications.-The cement should meet the requirements of the Standard Methods of Testing and Specifications for Cement !(see Appendix, p. 274), or as may be hereafter amended, the result of the joint labors of special committees of the American Society of Civil Engineers, American Society for Testing Materials, American Railway Engineering Association, and others. 


\section{AGGREGATES.}

Extreme care should be exercised in selecting the aggregates for mortar and concrete, and careful tests made of the materials for the purpose of determining their qualities and the grading necessary to secure maximum density ${ }^{1}$ or a minimum percentage of voids.

(a) Fine Aggregate should consist of sand, crushed stone, or gravel screening, graded from fine to coarse and passing when dry a screen having $\frac{1}{4}$-in. diameter holes; it preferably should be of siliceous material, and should be clean, coarse, free from dust, soft particles, vegetable loam or other deleterious matter and not more than 6 per cent should pass a sieve having 100 meshes per linear inch. Fine aggregates should always be tested.

Fine aggregates should be of such quality that mortar composed of one part Portland cement and three parts fine aggregate by weight when made into briquettes will show a tensile strength at least equal to the strength of 1:3 mortar of the same consistency made with the same cement and standard Ottawa sand. ${ }^{2}$ If the aggregate be of poorer quality the proportion of cement should be increased in the mortar to secure the desired strength.

If the strength developed by the aggregate in the $1: 3$ mortar is less than 70 per cent of the strength of the Ottawa-sand mortar, the material should be rejected. To avoid the removal of any coating on the grains, which may affect the strength, bank sands should not be dried before being made into mortar, but should contain natural moisture. The percentage of moisture may be determined upon a separate sample for correcting weight. From 10 to 40 per cent more water may be required in mixing bank or artificial sands than for standard Ottawa sand to produce the same consistency.

(b) Coarse Aggregate should consist of crushed stone or gravel which is retained on a screen having $\frac{1}{4}$-in. diameter holes and graded from the smallest to the largest particles; it should be clean, hard, durable, and free from all deleterious matter. Aggregates containing dust and soft, flat or elongated particles, should be excluded from important structures.

${ }^{1}$ A convenient coefficient of density is the ratio of the sum of the volumes of materials contained in a unit volume to the total unit volume.

${ }^{2} \mathrm{~A}$ natural sand obtained at Ottawa, Illinois, passing a screen having 20 meshes and retained on a screen having 30 meshes per linear inch; prepared and furnished by the Ottawa Silica Company, for 2 cents per pound f. o. b. cars, Ottawa, Illinois-under the direction of the, Special Committee on Uniform Tests of Cement of the American Society of Civil Engineers. 
The maximum size of the coarse aggregate is governed by the character of the construction.

For reinforced concrete and for small masses of unreinforced concrete, the aggregate must be small enough to produce with the mortar a homogeneous concrete of viscous consistency which will pass readily between and easily surround the reinforcement and fill all parts of the forms.

For concrete in large masses the size of the coarse aggregate may be increased, as a large aggregate produces a stronger concrete than a fine one, although it should be noted that the danger of separation from the mortar becomes greater as the size of the coarse aggregate increases.

Cinder concrete should not be used for reinforced concrete structures. It may be allowable in mass for very light loads or for fire protection purposes. The cinders used should be composed of hard, clean, vitreous clinker, free from sulphides, unburned coal or ashes.

\section{WATER.}

The water used in mixing concrete should be free from oil, acid, alkalies, or organic matter.

\section{METAL REINFORCEMENT.}

The Committee recommends as a suitable material for reinforcement, steel filling the requirements for structural steel reinforcement of the specifications adopted by the American Railway Engineering Association (Appendix, p. 274).

Where little bending or shaping is required, and also for reinforcement for shrinkage and temperature stresses, material filling the requirements of the specifications adopted by the American Railway Engineering Association for high-carbon steel (Appendix, p. 274) may be used, adopting the same unit stresses as hereinafter recommended for structural grade material.

For the reinforcement of slabs, small beams or minor details, or for reinforcement for shrinkage and temperature stresses, wire drawn from bars of the grade of rivet steel may be used, with the unit stresses hereinafter recommended.

The reinforcement should be free from excessive rust, scale, 
or coatings of any character which would tend to reduce or destroy the bond.

\section{Preparing and Placing Mortar and Concrete.}

\section{PROPORTIONS.}

The materials to be used in concrete should be carefully selected, of uniform quality, and proportioned with a view to securing as nearly, as possible a maximum density.

(a) Unit of Measure.-The unit of measure should be the cubic foot. A bag of cement, containing $94 \mathrm{lb}$. net, should be considered the equivalent of one cubic foot.

The measurement of the fine and coarse aggregates should be by loose volume.

(b) Relation of Fine and Coarse Aggregates. - The fine and coarse aggregates should be used in such relative proportions as will insure maximum density. In unimportant work it is sufficient to do this by individual judgment, using correspondingly higher proportions of cement; for important work these proportions should be carefully determined by density experiments and the sizing of the fine and coarse aggregates should be uniformly maintained or the proportions changed to meet the varying sizes.

(c) Relation of Cement and Aggregates-For reinforced concrete construction, one part of cement to a total of six parts of fine and coarse aggregates measured separately should generally be used. For columns, richer mixtures are generally preferable, and in massive masonry or rubble concrete a mixture of 1:9 or even 1:12 may be used.

These proportions should be determined by the strength or the wearing qualities required in the construction at the critical period of its use. Experienced judgment based on individual observation and tests of similar conditions in similar localities is an excellent guide as to the proper proportions for any particular case.

For all important construction, advance tests should be made of concrete of the materials, proportions and consistency to be used in the work. These tests should be made under laboratory conditions to obtain uniformity in mixing, proportioning and storage, and in case the results do not conform to the requirements of the work, aggregates of a better quality should be chosen or richer proportions used to obtain the desired results. 


\section{MIXING.}

The ingredients of concrete should be thoroughly mixed and the mixing should continue until the cement is uniformly distributed and the mass is uniform in color and homogeneous. As the maximum density and greatest strength of a given mixture depend largely on thorough and complete mixing, it is essential that the work of mixing should receive special attention and care.

Inasmuch as it is difficult to determine, by visual inspection, whether the concrete is uniformly mixed, especially where limestone or aggregates having the color of cement are used, it is essential that the mixing should occupy a definite period of time. The minimum time will depend on whether the mixing is done by machine or hand.

(a) Measuring Ingredients.-Methods of measurement of the proportions of the various ingredients should be used which will secure separate and uniform measurements of cement, fine aggregate, coarse aggregate, and water at all times.

(b) Machine Mixing.-When the conditions will permit, a machine mixer of a type which insures the uniform proportioning of the materials throughout the mass should be used, as a more uniform consistency can be thus obtained. The mixing should continue for a minimum time of at least one minute after all the ingredients are assembled in the mixer.

(c) Hand Mixing. - When it is necessary to mix by hand, the mixing should be on a water-tight platform and especial precautions should be taken to turn all the ingredients together at least six times and until they are homogeneous in appearance and color.

(d) Consistency.-The materials should be mixed wet enough to produce a concrete of such a consistency as will flow into the forms and about the metal reinforcement when used, and which, at the same time, can be conveyed from the mixer to the forms without separation of the coarse aggregate from the mortar.

(e) Retempering.--Mortar or concrete should not be remixed with water after it has partly set.

\section{PLACING CONCRETE.}

(a) Methods.-Concrete after the completion of the mixing should be handled rapidly, and in as small masses as is practicable, 
from the place of mixing to the place of final deposit, and under no circumstances should concrete be used that has partly set. A slow-setting cement should be used when a long time is likely to occur between mixing and placing.

Concrete should be deposited in such a manner as will permit the most thorough compacting; such as can be obtained by working with a straight shovel or slicing tool kept moving up and down until all the, ingredients have settled in their proper place by gravity and the surplus water has been forced to the surface. Special care should be exercised to prevent the formation of laitance, which hardens very slowly and forms a poor surface on which to deposit fresh concrete. All laitance should be removed.

Before depositing concrete, the reinforcement should be carefully placed in accordance with the plans, and adequate means provided to hold it in its proper position until the concrete has been deposited and compacted; care should be taken to see that the forms are substantial and thoroughly wetted (except in freezing weather) or oiled and that the space to be occupied by the concrete is free from débris. When the placing of concrete is suspended, all necessary grooves for joining future work should be made before the concrete has had time to set.

When work is resumed, concrete previously placed should be roughened, thoroughly cleansed of foreign material and laitance, thoroughly wetted and then slushed with a mortar consisting of one part Portland cement and not more than two parts fine aggregate.

The faces of concrete exposed to premature drying should be kept wet for a period of at least seven days.

(b) Freezing Weather.-Concrete should not be mixed or deposited at a freezing temperature, unless special precautions are taken to avoid the use of materials covered with ice crystals or containing frost, and to provide means to prevent the concrete from freezing after being placed in position and until it has thoroughly hardened.

As the coarse aggregate forms the greater portion of the concrete, it is particularly important that this material be heated to well above the freezing point.

(c) Rubble Concrete.-Where the concrete is to be deposited in massive work, its value may be improved and its cost mate- 
rially reduced by the use of clean stones thoroughly embedded in the concrete as near together as is possible and still entirely surrounded by concrete.

(d) Under Water.-In placing concrete under water it is essential to maintain still water at the place of deposit. The use of tremies, properly designed and operated, is a satisfactory method of placing concrete through water. The concrete should be mixed very wet (more so than is ordinarily permissible) so that it will flow readily through the tremie and into the place with practically a level surface.

The coarse aggregate should be smaller than ordinarily used, and never more than $1 \mathrm{in}$. in diameter. The use of gravel facilitates mixing and assists the flow of concrete through the tremie. The mouth of the tremie should be buried in the concrete so that it is at all times entirely sealed and the surrounding water prevented from forcing itself into the tremie; the concrete will then discharge without coming in contact with the water. The tremie should be suspended so that it can be lowered quickly when it is necessary either to choke off or prevent too rapid flow; the lateral flow should preferably be not over $15 \mathrm{ft}$.

The flow should be continuous in order to produce a monolithic mass and to prevent the formation of laitance in the interior.

In large structures it may be necessary to divide the mass of concrete into several small compartments or units, filling one at a time. With proper care it is possible in this manner to obtain as good results under water as in the air.

\section{Forms.}

Forms should be substantial and unyielding, so that the concrete shall conform to the designed dimensions and contours, and should be tight in order to prevent the leakage of mortar.

The time for removal of forms is one of the most important steps in the erection of a structure of concrete or reinforced concrete. Care should be taken to inspect the concrete and ascertain its hardness before removing the forms.

So many conditions affect the hardening of concrete, that the proper time for the removal of the forms should be decided by some competent and responsible person, especially where the atmospheric conditions are unfavorable. 
It may be stated in a general way that forms should remain in place longer for reinforced concrete than for plain or massive concrete, and that forms for floors, beams and similar horizontal structures should remain in place much longer than for vertical walls.

When the concrete gives a distinctive ring under the blow of a hammer, it is generally an indication that it has hardened sufficiently to permit the removal of the forms with safety. If, however, the temperature is such that there is any possibility that the concrete is frozen, this test is not a safe reliance, as frozen concrete may appear to be very hard.

\section{Details of Construction.}

\section{JOINTS.}

(a) Concrete.-For concrete construction it is desirable to cast the entire structure at one operation, but as this is not always possible, especially in large structures, it is necessary to stop the work at some convenient point. This should be selected so that the resulting joint may have the least possible effect on the strength of the structure. It is therefore recommended that the joint in columns be made flush with the lower side of the girders; that the joints in girders be at a point midway between supports, but should a beam intersect a girder at this point, the joint should be offset a distance equal to twice the width of the beam; that the joints in the members of a floor system should in general be made at or near the center of the span.

Joints in columns should be perpendicular to the axis of the column, and in girders, beams, and floor slabs, perpendicular to the plane of their surfaces.

Girders should never be constructed over freshly formed columns without permitting a period of at least two hours to elapse, thus providing for settlement or shrinkage in the columns.

Shrinkage and contraction joints may be necessary in concrete subject to great fluctuations in temperature. The frequency of these joints will depend, first, on the range of tern perature to which the concrete will be subjected, and second, on the quantity and position of the reinforcement, These joints should be determined and provided for in the design. In massive work, such as retaining walls, abutments, etc., built without rein- 
forcement, contraction joints should be provided, at intervals of from 25 to $50 \mathrm{ft}$. and with reinforcement from 50 to $80 \mathrm{ft}$. (the smaller the height and thickness, the closer the spacing), throughout the length of the structure. To provide against the structures being thrown out of line by unequal settlement, each section of the wall should be tongued and grooved into the adjoining section. A groove should be formed in the surface of the concrete at vertical joints in walls or abutments.

Shrinkage and contraction joints should be lubricated by either an application of petroleum residuum oil or a similar material so as to permit a free movement at the joint when the concrete expands or contracts.

The insertion of a sheet of copper or zinc or even tarred paper will be found advantageous securing expansion and contraction at the joint.

(b) Reinforcement.-Wherever it is necessary to splice tension reinforcement the length of lap should be determined on the basis of the safe bond stress, the stress in the bar and the shearing resistance of the concrete at the point of splice; or a connection should be made between the bars of sufficient strength to earry the stress. Splices at points of maximum stress should be avoided. In columns, bars more than $\frac{3}{4}$ in. in diameter not subject to tension should be properly squared and butted in a suitable sleeve; smaller bars may be treated as indicated for tension reinforcement or the stress may be cared for by embedment in large masses of concrete. At foundations, bearing plates should be provided for supporting the bars, or the bars may be carried into the footing a sufficient distance to transmit the stress of the steel to the concrete by means of the bearing and bond resistance; in no case shall the ends of the bars be permitted merely to rest on concrete.

\section{SHRINKAGE AND TEMPERATURE CHANGES.}

Shrinkage of concrete, due to hardening and contraction from temperature changes, causes cracks, the size of which depends on the extent of the mass. The resulting stresses are important in monolithic construction and should be considered carefully by the designer; they cannot be counteracted successfully, but the effects can be minimized. 
Large cracks produced by quick hardening or wide ranges of temperature can be broken up to some extent into small cracks by placing reinforcement in the concrete; in long continuous lengths of concrete, it is better to provide shrinkage joints at points in the structure where they will do little or no harm. Reinforcement is of assistance and permits longer distances between shrinkage joints than when no reinforcement is used.

Small masses or thin bodies of concrete should not be joined to larger or thicker masses without providing for shrinkage at such points. Fillets similar to those used in metal castings, but of larger dimensions, for gradually reducing from the thicker to the thinner body, are of advantage.

Shrinkage cracks are likely to occur at points where fresh concrete is joined to that which is set, and hence in placing the concrete, construction joints should be made on horizontal and vertical lines, and, if possible, at points where joints would naturally occur in dimension stone masonry.

\section{FIREPROOFING.}

The actual fire tests of concrete and reinforced concrete have been limited, but experience, together with the results of tests thus far made, indicates that concrete, on account of its low rate of heat conductivity and the fact that it is incombustible, may be used safely for fireproofing purposes.

The dehydration of concrete probably begins at about $500^{\circ}$ F. and is completed at about $900^{\circ} \mathrm{F}$., but experience indicates that the volatilization of the water absorbs heat from the surrounding mass, which, together with the resistance of the air cells, tends to increase the heat resistance of the concrete, so that the process of dehydration is very much retarded. The concrete that is actually affected by fire remains in position and affords protection to the concrete beneath it.

The thickness of the protective coating required depends on the probable duration of a fire which is likely to occur in the structure and should be based on the rate of heat conductivity. The question of the conductivity of concrete is one which requires further study and investigation before a definite rate for different classes of concrete can be fully established. 
However, for ordinary conditions it is recommended that the metal in girders and columns be protected by a minimum of 2 in. of concrete; that the metal in beams be protected by a minimum of $1 \frac{1}{2} \mathrm{in}$. of concrete, and that the metal in floor slabs be protected by a minimum of $1 \mathrm{in}$. of concrete.

It is recommended that in monolithic concrete columns, the concrete to a depth of $1 \frac{1}{2} \mathrm{in}$. be considered as protective covering and not included in the effective section.

It is recommended that the corners of columns, girders and beams be beveled or rounded, as a sharp corner is more seriously affected by fire than a round one.

\section{WATERPROOFING.}

Many expedients have been used to render concrete impervious to water under normal conditions, and also under pressure conditions that exist in reservoirs, dams and conduits of various kinds. Experience shows, however, that where mortar or concrete is proportioned to obtain the greatest practicable density and is mixed to a rather wet consistency, the resulting mortar or concrete is impervious under moderate pressure.

A concrete of dry consistency is more or less pervious to water, and compounds of various kinds have been mixed with the concrete, or applied as a wash to the surface for the purpose of making it water tight. Many of these compounds are of but temporary value, and in time lose their power of imparting impermeability to the concrete.

In the case of subways, long retaining walls and reservoirs, provided the concrete itself is impervious, cracks may be so reduced by horizontal and vertical reinforcement properly proportioned and located, that they are too minute to permit leakage, or are soon closed by infiltration of silt.

Coal-tar preparations applied either as a mastic or as a coating on felt or cloth fabric, are used for waterproofing, and should be proof against injury by liquids or gases.

For retaining and similar walls in direct contact with the earth, the application of one or two coatings of hot coal-tar pitch to the thoroughly dried surface of concrete is an efficient method of preventing the penetration of moisture from the earth. 


\section{SURFACE FINISH.}

Concrete is a material of an individual type and should not be used in imitation of other structural materials. One of the important problems connected with its use is the character of the finish of exposed surfaces. The finish of the surface should be determined before the concrete is placed, and the work conducted so as to make possible the finish desired. For many forms of construction the natural surface of the concrete is unobjectionable, but frequently the marks of the boards and the flat dead surface are displeasing, making some special treatment desirable. A treatment of the surface either by scrubbing it while green or by tooling it after it is hard, which removes the film of mortar and brings the aggregates of the concrete into relief, is frequently used to remove the form markings, break the monotonous appearance of the surface, and make it more pleasing. The plastering of surfaces should be avoided, for even if carefully done, it is likely to peel off under the action of frost or temperature changes.

\section{Design.}

\section{MASSIVE CONCRETE.}

In the design of massive or plain concrete, no account should be taken of the tensile strength of the material, and sections should usually be proportioned so as to avoid tensile stresses except in slight amounts to resist indirect stresses. This will generally be accomplished, in the case of rectangular shapes, if the line of pressure is kept within the middle third of the section, but in very large structures, such as high masoniry dams, a more exact analysis may be required. Structures of massive concrete are able to resist unbalanced lateral forces by reason of their weight; hence the element of weight rather than strength often determines the design. A relatively cheap and weak concrete, therefore, will often be suitable for massive concrete structures.

It is desirable generally to provide joints at intervals to localize the effect of contraction.

Massive concrete is suitable for dams, retaining walls, and piers and short columns in which the ratio of length to least 
width is relatively small. Under ordinary conditions this ratio should not exceed six. It is also suitable for arches of moderate span, where the conditions as to foundations are favorable.

\section{REINFORCED CONCRETE.}

By the use of metal reinforcement to resist the principal tensile stresses, concrete becomes available for general use in a great variety of structures and structural forms. This combination of concrete and metal is particularly advantageous in the beam where both compression and tension exist; it is also advantageous in the column where the main stresses are compressive, but where cross-bending may exist. The theory of design, therefore, will relate mainly to the analysis of beams and columns.

\section{GENERAL ASSUMPTIONS.}

(a) Loads.-The loads or forces to be resisted consist of:

1. The dead load, which includes the weight of the structure and fixed loads and forces.

2. The live load or the loads and forces which are variable. The dynamic effect of the live load will often require consideration. Any allowance for the dynamic effect is preferably taken into account by adding the desired amount to the live load or to the live load stresses. The working stresses hereinafter recommended are intended to apply to the equivalent static stresses thus determined.

In the case of high buildings the live load on columns may be reduced in accordance with the usual practice.

(b) Lengths of Beams and Columns.-The span length for beams and slabs shall be taken as the distance from center to center of supports, but need not be taken to exceed the clear span plus the depth of beam or slab. Brackets shall not be considered as reducing the clear span in the sense here intended.

The length of columns shall be taken as the maximum unsupported length.

(c) Internal Stresses.-As a basis for calculations relating to 
the strength of structures, the following assumptions are recommended:

1. Calculations will be made with reference to working stresses and safe loads rather than with reference to ultimate strength and ultimate loads.

2. A plane section before bending remains plane after bending.

3. The modulus of elasticity of concrete in compression within the usual limits of working stresses, is constant. The distribution of compressive stresses in beams therefore is rectilinear.

3. In calculating the moment of resistance of beams the tensile stresses in the concrete are neglected.

5. Perfect adhesion is assumed between concrete and reinforcement. Under compressive stresses the two materials are therefore stressed in proportion to their moduli of elasticity.

6. The ratio of the modulus of elasticity of steel to the modulus of elasticity of concrete is taken at 15 except as modified in Chapter VIII, Section 8.

7. Initial stress in the reinforcement due to contraction or expansion in the concrete is neglected.

It is recognized that some of the assumptions given herein are not entirely borne out by experimental data. They are given in the interest of simplicity and uniformity, and variations from exact conditions are taken into account in the selection of formulas and working stresses.

The deflection of beams is affected by the tensile strength developed throughout the length of the beam. For calculations of deflections a value of 8 for the ratio of the moduli will give results corresponding approximately with the actual conditions.

\section{T-BEAMS.}

In beam and slab construction, an effective bond should be provided at the junction of the beam and slab. When the principal slab reinforcement is parallel to the beam, transverse reinforcement should be used extending over the beam and well into the slab. 
Where adequate bond and shearing resistance between slab and web of beam is provided, the slab may be considered as an integral part of the beam, but its effective width shall be determined by the following rules:

(a) It shall not exceed one-fourth of the span length of the beam;

(b) Its overhanging width on either side of the web shall not exceed four times the thickness of the slab.

In the design of T-beams acting as continuous beams, due consideration should be given to the compressive stresses at the support.

Beams in which the T-form is used only for the purpose of providing additional compression area of concrete should preferably have a width of flange not more than three times the width of the stem and a thickness of flange not less than one-third of the depth of the beam. Both in this form and in the beam and slab form the web stresses and the limitations in placing and spacing the longitudinal reinforcement will piobably be controlling factors in design.

\section{FLOOR SLABS.}

Floor slabs should be designed and reinforced as continuous over the supports. If the length of the slab exceeds 1.5 times its width the entire load should be carried by transverse reinforcement. Square slabs may well be reinforced in both directions. ${ }^{1}$

${ }_{1}^{1}$ The exact distribution of load on square and rectangular slabs, supported on four sides and reinforced in both directions cannot readily be determined. The following method of calculation is recognized to be faulty, but it is offered as a tentative method which will give results on the safe side. The distribution of load is first to be determined by the formula

$$
r=\frac{1^{4}}{1^{4}+b^{4}}
$$

in which $r=$ proportion of load carried by the transverse reinforcement, $1=$ length and $b=$ breadth of slab. For various ratio of $1 / \mathrm{b}$ the values of $r$ are as follows:

$\begin{array}{lc}1 / b & r \\ 1 & 0.50 \\ 1.1 & 0.59 \\ 1.2 & 0.67 \\ 1.3 & 0.75 \\ 1.4 & 0.80 \\ 1.5 & 0.83\end{array}$

Using the values above specified each set of reinforcement is to be calculated in the same manner as slabs having supports on two sides only, but the total amount of reinforcement thus determined may be reduced 25 per cent, by gradually increasing the rod spacing from the third point to the edge of the slab. 
The continuous flat slab with multiple-way reinforcement is a type of construction used quite extensively, which has recognized advantages for special conditions, as in the case of warehouses with large, open floor space. At present a considerable difference of opinion exists among engineers as to the formulas and constants which should be used, but experience and tests are accumulating data which it is hoped will in the near future permit the formulation of the principles of design for this form of construction.

The loads carried to beams by slabs which are reinforced in two directions will not be uniformly distributed to the supporting beam and its distribution will depend on the relative stiffness of the slab and the supporting beam. The distribution under ordinary conditions of construction may be expected to be that in which the load on the beam varies in accordance with the ordinates of a parabola having its vertex at the middle of the span. For any given design, the probable distribution should be ascertained and the moments in the beam calculated accordingly.

\section{CONTINUOUS BEAMS AND SLABS.}

When the beam or slab is continuous over its supports, reinforcement should be fully provided at points of negative moment, and the stresses in concrete recommended in Chapter VIII, Section 4, should not be exceeded. In computing the positive and negative moments in beams and slabs continuous over several supports, due to uniformly distributed loads, the following rules are recommended:

(a) That for floor slabs the bending moments at center and at support be taken at $\frac{\mathrm{wl}^{2}}{12}$ for both dead and live loads, where $\mathrm{w}$ represents the load per linear foot and 1 the span length.

(b) That for beams the bending moment at center and at support for interior spans be taken at $\frac{\mathrm{wl}^{2}}{12}$, and for ends spans it be taken at $\frac{\mathrm{wl}^{2}}{10}$ for center and adjoining support, for both dead and live loads. 
(c) In the case of beams and slabs continuous for two spans only, the bending moment at the central support should be taken as $\frac{\mathrm{wl}^{2}}{8}$ and near the middle of the span as $\frac{\mathrm{wl}^{2}}{10}$.

(d) At the ends of continuous beams, the amount of negative moment which will be developed will depend on the condition of restraint or fixedness, and this will depend on the form of construction used. There will usually be some restraint and there is likely to be considerable. Provision should be made for the negative bending moment, but as its amount will depend on the form of construction the coefficient eannot be specified here and must be left to the judgment of the designer.

For spans of unusual length, more exact calculations should be made. Special consideration is also required in the case of concentrated loads.

Even if the center of the span is designed for a greater bending moment than is called for by $(a)$ or $(b)$, the negative moment at the support should not be taken as less than the values there given.

Where beams are reinforced un the compression side, the steel may be assumed to carry its proportion of stress in accordance with the provisions of Chapter VII, Section 3, c-6. In the case of cantilever and continuous beams, tensile and compressive reinforcement over supports must extend sufficiently beyond the support and beyond the point of infection to develop the requisite bond strength.

\section{BOND STRENGTH AND SPACING OF REINFORCEMENT.}

Adequate bond strength should be provided. The formula hereinafter given for bond stresses in beams is for straight longitudinal bars. In beams in which a portion of the reinforcement is bent up near the end, the bond stress at places in both the straight bars and the bent bars will be considerably greater than for all the bars straight, and the stress at some point may be several times as much as that found by considering the stress to be uniformly distributed along the bar. In restrained and canti- 
lever beams full tensile stress exists in the reinforcing bars at the point of support and the bars must be anchored in the support sufficiently to develop this stress.

In case of anchorage of bars, an additional length of bar must be provided beyond that found on the assumption of uniform bond stress, for the reason that before the bond resistance at the end of the bar can be developed the bar may have begun to slip at another point and "running" resistance is less than the resistance before slip begins.

Where high bond resistance is required, the deformed bar is a suitable means of supplying the necessary strength. But it should be recognized that even with a deformed bar initial slip occurs at early loads, and that the ultimate loads obtained in the usual tests for bond resistance may be misleading. Adequate bond strength throughout the length of a bar is preferable to end anchorage, but, as an additional safeguard, such anchorage may properly be used in special cases. Anchorage furnished by short bends at a right angle is less effective than hooks consisting of turns through $180 \mathrm{deg}$.

The lateral spacing of parallel bars should not be less than three diameters, from center to center, nor should the distance from the side of the beam to the center of the nearest bar be less than two diameters. The clear spacing between two layers of bars should not be less than 1 in. The use of more than two layers is to be discouraged, unless the layers are tied together by adequate metal connections, particularly at and near points where bars are bent up or bent down.

\section{DIAGONAL TENSION AND SHEAR.}

When a reinforced concrete beam is subjected to flexural action, diagonal tensile stresses are set up. If, in a beam not having web reinforcement, these stresses exceed the tensile strength of the concrete, failure of the beam will ensue. When web reinforcement made up of stirrups or of diagonal bars secured to the longitudinal reinforcement, or of longitudinal reinforcing bars bent up at several points is used, new conditions prevail, but even in this case at the beginning of loading the diagonal tension developed is taken principally by the concrete, the deformations which are developed in the concrete permitting but little stress to be taken 
by the web reinforcement. When the resistance of the concrete to the diagonal tension is overcome at any point in the depth of the beam, greater stress is at once set up in the web reinforcement.

For homogeneous beams the analytical treatment of diagona tension is not very complex - the diagonal tensile stress is a function of the horizontal and vertical shearing stresses and of the horizontal tensile stress at the point considered, and as the intensity of these three stresses varies from the neutral axis to the remotest fiber, the intensity of the diagonal tension will be different at different points in the section and will change with different proportionate dimensions of length to depth of beam. For the composite structure of reinforced concrete beams, an analysis of the web stresses, and particularly of the diagonal tensile stresses, is very complex; and when the variations due to a change from no horizontal tensile stress in the concrete at remotest fiber to the presence of horizontal tensile stress at some point below the neutral axis are considered, the problem becomes more complex and indefinite. Under these circumstances, in designing, recourse is had to the use of the calculated vertical shearing stress as a means of comparing or measuring the diagonal tensile stresses developed, it being understood that the vertical shearing stress is not the numerical equivalent of the diagonal tensile stress and even that there is not a constant ratio between them. It is here recommended that the maximum vertical shearing stress in a section be used as the means of comparison of the resistance to diagonal tensile stress developed in the concrete in beams not having web reinforcement.

Even after the concrete has reached its limit of resistance to diagonal tension, if the beam has web reinforcement, conditions of beam action will continue to prevail at least through the compression area, and the web reinforcement will be called on to resist only a part of the web stresses. From experiments with beams it is concluded that it is safe practice to use only two-thirds of the external vertical shear in making calculations of the stresses that come on stirrups, diagonal web pieces, and bent-up bars, and it is here recommended for calculations in designing that two-thirds of the external vertical shear be taken as producing stresses in web reinforcement.

Experiments bearing on the design of details of web rein- 
forcement are not yet complete enough to allow more than general and tentative recommendations to be made. It is well established, however, that vertical members attached to or looped about horizontal members, inclined members secured to horizontal members in such a way as to insure against slip, and the bending of a part of the longitudinal reinforcemen' at an angle, will increase the strength of a beam against failure by diagonal tension, and that a well-designed and well-distributed web reinforcement may under the best conditions increase the total vertical shear carried to a value as much as three times that obtained when the bars are all horizontal and no web reinforcement is used. Where vertical stirrups are used without being secured to the longitudinal reinforcement, the force transmitted between longitudinal bar and stirrup must not be greater than can be taken through the concrete, and care must be taken to provide for the larger bond stress developed in the longitudinal bars with this construction than exists in the absence of stirrups. Sufficient bond resistance between the concrete and the stirrups or diagonals must be provided. Where the longitudinal bars are bent up, the points of bending of the several bars should be distributed along a portion of the length of the beam in such a way as to give efficient web reinforcement over the portion of the length of the beam in which it is needed. The higher resistance to diagonal tension failures given by unit frames having the stirrups and bent-up bars securely connected together both longitudinally and laterally is worthy of recognition. It is necessary that a limit be placed on the amount of shear which may be allowed in a beam; for when web reinforcement sufficiently efficient to give very high web resistance is used, at the higher stresses the concrete in the beam becomes checked and cracked in such a way as to endanger its durability as well as its strength.

The section to be taken as the critical section in the calculation of shearing stresses will generally be the one having the maximum vertical shear, though experiments show that the section at which diagonal tension failures occur is not just at a support even though the shear at the latter point be much greater.

The longitudinal spacing of stirrups or diagonal members or the distribution of the points of bending of adjacent bent-up bars should not exceed three-fourths the depth of the beam. 
It is important that adequate bond strength or anchorage be provided to develop fully the assumed strength of all web reinforcement.

It should be noted that it is on the tension side of a beam that diagonal tension develops in a critical way, and that the proper connection must always be made between stirrups or other web reinforcement and the longitudinal tension reinforcement, whether the latter is on the lower side of the beam or on its upper side. Where negative moment exists, as is the case near the supports in a continuous beam, web reinforcement to be effective must be looped over or wrapped around or be connected with the longitudinal tension reinforcing bars at the top of the beam in the same way as is necessary at the bottom of the beam at sections where the bending moment is positive and the tension reinforcing bars are at the bottom of the beam.

Inasmuch as the smaller the longitudinal deformations in the horizontal reinforcement are, the less the tendency for the formation of diagonal cracks, a beam will be strengthened against diagonal tension failure by so arranging and proportioning the horizontal reinforcement that the unit stresses at points of large shear shall be relatively low.

Where pure shearing stress occurs, or shearing stress combined with but a small amount of tensile stress in the concrete, as when a concentrated load rests on a slab or other forms of punching shear are produced, or in the case of compression pieces, the element of tension will not need consideration, and the permissible limit of the shearing stress will be higher than the allowable limit when this stress is used as a means of comparing diagonal tensile stress. The working values recommended are given in Chapter VIII, Working Stresses.

\section{COLUMNS.}

By columns are meant compression members of which the ratio of unsupported length to least width exceeds about six, and which are provided with reinforcement of one of the forms hereafter described.

It is recommended that the ratio of unsupported length of column to its least width be limited to 15 .

The effective area of the column shall be taken as the area 
within the protective covering, as defined an Chapter VI, Section 3 , or in the case of hooped columns or columns reinforced with structural shapes it shall be taken as the area within the hooping or structural shapes.

Columns may be reinforced by longitudinal bars, by bands, hoops, or spirals, together with longitudinal bars, or by structural forms which in themselves are sufficiently rigid to act as columns. The general effect of closely spaced hooping is greatly to increase the "toughness" of the column and its ultimate strength, but hooping has little effect on its behavior within the limit of elasticity. It thus renders the concrete a safer and more reliable material and should permit the use of a somewhat higher working stress. The beneficial effects of "toughening" are adequately provided by a moderate amount of hooping, a larger amount serving mainly to increase the ultimate strength and the possible deformation before ultimate failure.

Composite columns of structural steel and concrete in which the steel forms a column by itself should be designed with caution. To classify this type as a concrete column reinforced with structural steel is hardly permissible, as the steel will generally take the greater part of the load. When this type of column is used the concrete should not be relied on to tie the steel units together or to transmit stresses from one unit to another. The units should be adequately tied together by tie plates or lattice bars, which, together with other details, such as splices, etc., should be designed in conformity with standard practice for structural steel. The concrete may exert a beneficial effect in restraining the steel from lateral deflection and also in increasing the carrying capacity of the column. The proportion of load to be carried by the concrete will depend on the form of the column and the method of construction. Generally for high percentages of steel the concrete will develop relatively low unitstresses, and caution should be used in placing dependence on the concrete.

The following recommendations are made for the relative working stresses in the concrete for the several types of columns:

(a) Columns with longitudinal reinforcement only, to the extent of not less than 1 per cent and not more 
than 4 per cent of the unit stress recommended for axial compression in Chapter VIII, Section 3.

(b) Columns with reinforcement of bands, hoops or spirals hereinafter specified, stress̀es 20 per cent higher than given for $(a)$, provided the ratio of unsupported length of column to diameter of the hooped core is not more than 8 .

(c) Columns reinforced with not less than 1 per cent and not more than 4 per cent of longitudinal bars and with bands, hoops or spirals, as hereinafter specified; stresses 45 per cent higher than given for $(a)$, provided the ratio of unsupported length of column to diameter of the hooped core is not more than 8 .

The foregoing recommendations are based on the following conditions:

In all cases longitudinal reinforcement is assumed to carry its proportion of stress in accordance with Section 3. The hoops or bands are not to be counted on directly as adding to the strength of the column.

Bars composing longitudinal reinforcement shall be straight and shall have sufficient lateral support to be securely held in place until the concrete has set.

Where hooping is used, the total amount of such reinforcement shall be not less than 1 per cent of the volume of the column, enclosed. The clear spacing of such hooping shall be not greater than one-sixth the diameter of the enclosed column and preferably not greater than one-tenth, and in no case more than $2 \frac{1}{2}$ in. Hooping is to be circular and the ends of bands must be united in such a way as to develop their full strength. Adequate means must be provided to hold bands or hoops in place so as to form a column, the core of which shall be straight and well centered. The strength of hooped columns depends very much upon the ratio of length to diameter of hooped core, and the strength due to hooping decreases rapidly as this ratio increases beyond five. The working stresses recommended are for hooped columns with a length of not more than eight diameters of the hooped core.

Bending stresses due to eccentric loads and lateral forces must be provided for by increasing the section until the maximum stress does not exceed the values above specified; and 
where tension is possible in the longitudinal bars adequate connection between the ends of the bars must be provided to take this tension.

\section{REINFORCING FOR SHRINKAGE AND TEMPERATURE STRESSES.}

When areas of concrete too large to expand and contract freely as a whole are exposed to atmospheric conditions, the changes of form due to shrinkage (resulting from hardening) and to action of temperature are such that cracks may occur in the mass, unless precautions are taken to distribute the stresses so as to prevent the cracks altogether or to render them very small. The distance apart of the cracks, and consequently their size, will be directly proportional to the diameter of the reinforcement and to the tensile strength of the concrete, and inversely proportional to the percentage of reinforcement and also to its bond resistance per unit of surface area. To be most effective, therefore, reinforcement (in amount generally not less than one-third of one per cent) of a form which will develop a high bond resistance should be placed near the exposed surface and be well distributed. The allowable size and spacing of cracks depends on various considerations, such as the necessity for water-tightness, the importance of appearance of the surface, and the atmospheric changes.

\section{Working Stresses.}

\section{GENERAL ASSUMPTIONS.}

The following working stresses are recommended for static loads. Proper allowances for vibration and impact are to be added to live loads where necessary to produce an equivalent static load before applying the unit stresses in proportioning parts.

In selecting the permissible working stress to be allowed on concrete, we should be guided by the working stresses usually allowed for other materials of construction, so that all structures of the same class but composed of different materials may have approximately the same degree of safety.

The following recommendations as to allowable stresses are given in the form of percentages of the ultimate strength of the particular concrete which is to be used; this ultimate strength is 
to be that developed in cylinders 8 in. in diameter and 16 in. long, of the consistency described in Chapter IV, Section $2(a)$, made and stored under laboratory conditions, at an age of 28 days. In the absence of definite knowledge in advance of construction as to just what strength may be expected, the Committee submits the following values as those which should be obtained with materials and workmanship in accordance with the recommendations of this report.

Although occasional tests may show higher results than those here given, the Committee recommends that these values should be the maximum used in design.

Table of Strengths of Different Mixtures of Concrete. (In Pounds per Square Inch.)

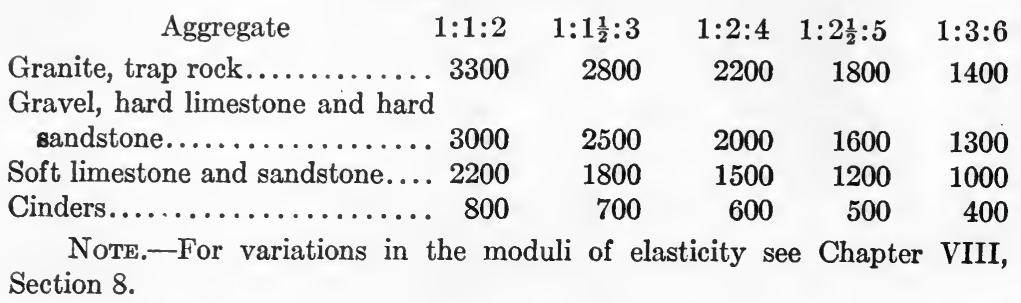

\section{BEARING.}

When compression is applied to a surface of concrete of at least twice the loaded area, a stress of 32.5 per cent of the compressive strength may be allowed.

\section{AXIAL COMPRESSION.}

For concentric compression on a plain concrete column or pier, the length of which does not exceed 12 diameters, 22.5 per cent of the compressive strength may be allowed.

For other forms of columns the stresses obtained from the ratios given in Chapter VII, Section 9, may govern.

\section{COMPRESSION IN EXTREME FIBER.}

The extreme fiber stress of a beam, calculated on the assumption of a constant modulus of elasticity for concrete under working stresses may be allowed to reach 32.5 per cent of the compressive strength. Adjacent to the support of continuous beams stresses 15 per cent higher may be used. 
5. SHEAR AND DIAGONAL TENSION.

In calculations on beams in which the maximum shearing stress in a section is used as the means of measuring the resistance to diagonal tension stress, the following allowable values for the maximum vertical shearing stress are recommended:

(a) For beams with horizontal bars only and without web reinforcement calculated by the method given in the Appendix, Formula (22), 2 per cent of the compressive strength.

(b) For beams thoroughly reinforced with web reinforcement, the value of the shearing stress calculated as for $(a)$ (that is, using the total external vertical shear in the Formula (22) for shearing unit stress) must not exceed 6 per cent of the compressive strength. The web reinforcement, exclusive of bent-up bars, in this case shall be proportioned to resist two-thirds of the external vertical shear in the formulas given in the Appendix, Formula (24) or (25).

(c) For beams in which part of the longitudinal reinforcement is used in the form of bent-up bars distributed over a portion of the beam in a way covering the requirements for this type of web reinforcement, the limit of maximum vertical shearing stress (the stress calculated as for $(a)$ ), 3 per cent of the compressive strength.

(d) Where punching shear occurs, that is, shearing stress uncombined with compression normal to the shearing surface, and with all tension normal to the shearing plane provided for by reinforcement, a shearing stress of 6 per cent of the compressive strength may be allowed.

\section{BOND.}

The bond stress between concrete and plain reinforcing bars may be assumed at 4 per cent of the compressive strength, or 2 per cent in the case of drawn wire.

\section{REINFORCEMENT.}

The tensile or compressive stress in steel should not exceed $16,000 \mathrm{lb}$. per sq. in.

In structural steel members the working stresses adopted by the American Railway Engineering Association are recommended. 


\section{MODULUS OF ELASTICITY.}

The value of the modulus of elasticity of concrete has a wide range, depending on the materials used, the age, the range of stresses between which it is considered, as well as other conditions. It is recommended that in computations for the position of the neutral axis and for the resisting moment of beams and for compression of concrete in columns it be assumed as:

(a) One-fifteenth that of steel, when the strength of the concrete is taken as $2200 \mathrm{lb}$. per sq. in. or less.

(b) One-twelfth that of steel, when the strength of the concrete is taken as greater than $2200 \mathrm{lb}$. per sq. in. or less than $2900 \mathrm{lb}$. per sq. in., and

(c) One-tenth that of steel, when the strength of the concrete is taken as greater than $2900 \mathrm{lb}$. per sq. in.

Although not rigorously accurate, these assumptions will give safe results. For the deflection of beams which are free to move longitudinally at the supports, in using formulas for deflection which do not take into account the tensile strength developed in the concrete, a modulus of one-eighth of that of steel is recommended.

Respectfully submitted,

\section{J. R. WORCESTER,}

Chairman.

RichaRd L. HUMphrey, Secretary.

J. E. Greiner, W. K. HatT, OLAF Hoff, Robert W. Lesley, A. N. Talbot, William B. Fuller, E. Lee Heidenreich, A. L. Johnson, Gaetano Lanza Edgar Marburg, Charles M. Mulls, Leon S. Moisseiff, Henry H. QUimby,
Emil Swensson, Vice-Chairman.
W. Purves Taylor, SANFord E. Thompson, F. E. Turneaure, Samuel Tobias Wagner,

George S. Webster,

C. W. Boynton,

F. E. Schall,

G. H. ScRibner, Jr.,

F. L. Thompson,

Јов TUTHILL,

R. E. GRIFFiths, Edward M. HaGar, S. B. NewberRy. 


\section{Appendix.}

\section{STANDARD SPECIFICATIONS.}

(a) Cement. $^{1}$

\section{(b) Metal Reinforcement. ${ }^{2}$}

6. Steel shall be made by the open-hearth process. Rerolled material will not be accepted.

7. Plates and shapes used for reinforcement shall be of structural steel only. Bars and wire may be structural steel or high-carbon steel.

8. The chemical and physical properties shall conform to the following limits:

\begin{tabular}{|c|c|c|}
\hline Elements Considered. & Structural Steel. & High-Carbon Steel. \\
\hline 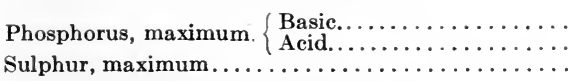 & $\begin{array}{l}0.04 \text { per cent. } \\
0.06 \\
0.05\end{array}$ & $\begin{array}{l}0.04 \text { per cent. } \\
0.06 \\
0.05\end{array}$ \\
\hline 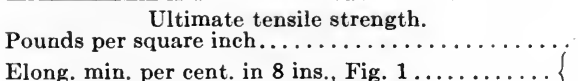 & $\begin{array}{c}\text { Desired } \\
60,000 \\
1,500,000^{*} \\
\end{array}$ & $\begin{array}{l}\text { Desired } \\
88,000 \\
1,000,000\end{array}$ \\
\hline 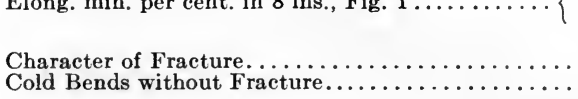 & \begin{tabular}{|} 
Ult. tensilestrength \\
Silky \\
$180^{\circ}$ flat $\dagger$
\end{tabular} & $\begin{array}{l}\text { Ult. tensile strength } \\
\text { Silky or finely } \\
\text { granular } \\
180^{\circ} \mathrm{d}=4 \mathrm{t} \ddagger\end{array}$ \\
\hline
\end{tabular}

* See Paragraph 15. † See Paragraphs 16 and 17. $\ddagger$ "d=4t" signifies "around a pin whose diameter is four times the thickness of the specimen."

9. The yield point for bars and wire, as indicated by the drop of the beam, shall be not less than 60 per cent of the ultimate tensile strength.

10. If the ultimate strength varies more than $4000 \mathrm{lb}$. for structural steel or $6000 \mathrm{lb}$. for high-carbon steel, a retest shall be made on the same gage, which, to be acceptable, shall be within $5000 \mathrm{lb}$. for structural steel, or $8000 \mathrm{lb}$. for high-carbon steel, of the desired ultimate.

11. Chemical determinations of the percentages of carbon,

${ }^{1}$ Adopted August 16, 1909, by the American Society for Testing Materials. See YearBook for 1913, pp. 254-258.

2 Adopted March 16, 1910, by the American Railway Engineering Association. 
phosphorus, sulphur and manganese shall be made by the manufacturer from a test ingot taken at the time of the pouring of each melt of steel, and a correct copy of such analysis shall be furnished to the engineer or his inspector. Check analyses shall be made from finished material, if called for, in which case an excess of 25 per cent above the required limit will be allowed.

12. Plates, Shapes and Bars.-Specimens for tensile and bending tests for plates and shapes shall be made by cutting coupons from the finished product, which shall have both faces rolled and both edges milled to the form shown by Fig. 1; or with both edges parallel; or they may be turned to a diameter of $\frac{3}{4}$ in. with enlarged ends.

13. Bars shall be tested in their finished form.

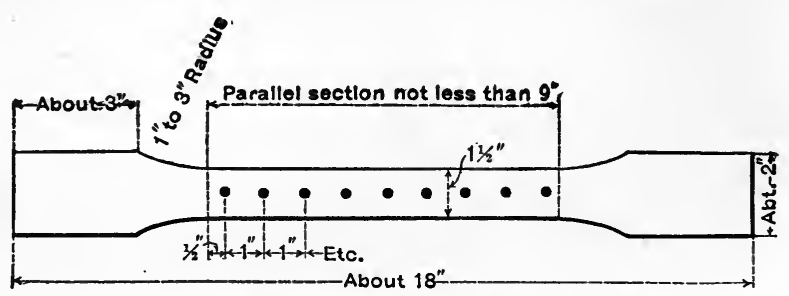

Fig. 1.-Test Piece for Tension Test.

14. At least one tensile and one bending test shall be made from each melt of steel as rolled. In case steel differing $\frac{3}{8}$-in. and more in thickness is rolled from one melt, a test shall be made from the thickest and thinnest material rolled.

15. For material less than $\frac{5}{16}$ in. and more than $\frac{3}{4}$ in. in thickness, the following modifications will be allowed in the requirements for elongation:

(a) For each $\frac{1}{16}$ in. in thickness below $\frac{5}{16}$ in. a deduction of 2.5 will be allowed from the specified percentage.

(b) For each $\frac{1}{8}$ in. in thickness above $\frac{3}{4}$ in., a deduction of 1 will be allowed from the specified percentage.

16. Bending tests may be made by pressure or by blows. Shapes and bars less than 1 in. thick shall bend as called for in Paragraph 8.

17. Test specimens 1 in. thick and over shall bend cold 
$180 \mathrm{deg}$. around a pin, the diameter of which, for structural steel, is twice the thickness of the specimen, and for high-carbon steel, is six times the thickness of the specimen, without fracture on the outside of the bend.

18. Finished material shall be free from injurious seams, flaws, cracks, defective edges or other defects, and have a smooth, uniform and workmanlike finish.

19. Every finished piece of steel shall have the melt number and the name of the manufacturer stamped or rolled upon it, except that bar steel and other small parts may be bundled with the above marks on an attached metal tag.

20. Material which, subsequent to the above tests at the mills and its acceptance there, develops weak spots, brittleness, cracks or other imperfections, or is!found to have injurious defects, will be rejected and shall be replaced by the manufacturer at his own cost.

21. All reinforcing steel shall be free from excessive rust, loose scale, or other coatings of any character which would reduce or destroy the bond.

\section{SUGGESTED FORMULAS FOR REINFORCED CON- CRETE CONSTRUCTION.}

These formulas are based on the assumptions and principles given in the chapter on design.

\section{(a) Standard Notation.}

1. Rectangular Beams.

The following notation is recommended:

$\mathrm{f}_{\mathrm{s}}=$ tensile unit stress in steel.

$\mathrm{f}_{\mathrm{c}}=$ compressive unit stress in concrete.

$\mathrm{E}_{\mathrm{s}}=$ modulus of elasticity of steel.

$\mathrm{E}_{\mathrm{c}}=$ modulus of elasticity of concrete.

$\mathrm{n}=\frac{\mathrm{E}_{\mathrm{s}}}{\mathrm{E}_{\mathrm{c}}}$

$\mathrm{M}=$ moment of resistance, or bending moment in general.

$\mathrm{A}=$ steel area. 
$\mathrm{b}=$ breadth of beam.

$\mathrm{d}=$ depth of beam to center of steel.

$\mathrm{k}$ = ratio of depth of neutral axis to effective depth $\mathrm{d}$

$\mathrm{z} \quad=$ depth of resultant compression below top.

$\mathrm{j} \quad=$ ratio of lever arm of resisting couple to depth $\mathrm{d}$.

$\mathrm{jd}=\mathrm{d}-\mathrm{z}=$ arm of resisting couple.

$\mathrm{p}=$ steel ratio (not percentage).

2. T-Beams.

$\mathrm{b}=$ width of flange.

$\mathrm{b}^{\prime}=$ width of stem.

$\mathrm{t}=$ thickness of flange.

3. Beams Reinforced for Compression.

$\mathrm{A}^{\prime}=$ area of compressive steel.

$\mathrm{p}^{\prime}=$ steel ratio for compressive steel.

$\mathrm{f}_{\mathrm{s}}{ }^{\prime}=$ compressive unit stress in steel.

$\mathrm{C}=$ total compressive stress in concrete.

$\mathrm{C}^{\prime}=$ total compressive stress in steel.

$\mathrm{d}^{\prime}=$ depth to center of compressive steel.

$\mathrm{z}=$ depth to resultant of $\mathrm{C}$ and $\mathrm{C}^{\prime}$.

4. Shear and Bond.

$$
\begin{aligned}
& \mathrm{V}=\text { total shear. } \\
& \mathrm{v}=\text { shearing unit stress. } \\
& \mathrm{u}=\text { bond stress per unit area of bar. } \\
& \mathrm{o}=\text { circumference or perimeter of bar. } \\
& \vec{\Sigma}_{0}=\text { sum of the perimeters of all bars. }
\end{aligned}
$$

5. Columns.
$\mathrm{A}=$ total net area.
$\mathrm{A}_{\mathrm{s}}=$ area of longitudinal steel.
$\mathrm{A}_{\mathrm{c}}=$ area of concrete.
$\mathrm{P}=$ total safe load. 
(b) Formulas.

1. Rectangular Beams.

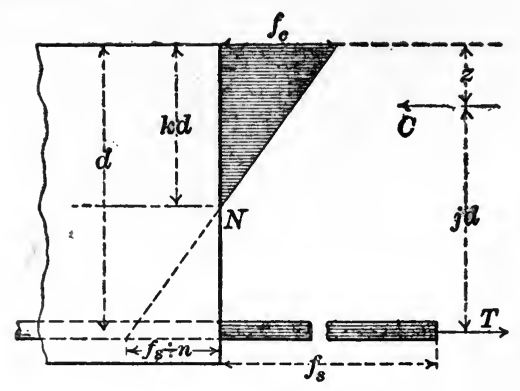

FIG. 2.

Position of neutral axis,

$$
\mathrm{k}=\sqrt{2 \mathrm{pn}+(\mathrm{pn})^{2}}-\mathrm{pn} .
$$

Arm of resisting couple,

$$
\mathrm{j}=1-\frac{1}{3} \mathrm{k} \text {. }
$$

[For $f_{s}=15000$ to 16000 and $f_{c}=600$ to $650, j$ may be taken at $\frac{7}{8}$.]

Fiber stresses,

$$
\begin{aligned}
& \mathrm{f}_{8}=\frac{M}{A j d}=\frac{M}{p_{j b d^{2}}} . \\
& \mathrm{f}_{\mathrm{c}}=\frac{2 \mathrm{M}}{\mathrm{jkbd}^{2}}=\frac{2 \mathrm{pf}_{\mathrm{s}}}{\mathrm{jk}} .
\end{aligned}
$$

Steel ratio, for balanced reinforcement,

2. T-Beams.

$$
p=\frac{1}{2} \cdot \frac{1}{\frac{f_{s}}{f_{c}}\left(\frac{f_{s}}{n f_{c}}+1\right)} .
$$

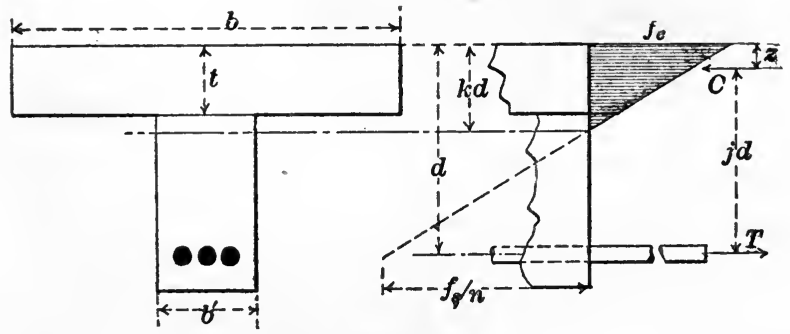

FIG. 3.

Case I. When the neutral axis lies in the flange, use the formulas for rectangular beams. 
Report on Concrete and Reinforced Concrete. 279

Case II. When the neutral axis lies in the stem.

The following formulas neglect the compression in the stem. Position of neutral axis,

$$
\mathrm{kd}=\frac{2 \mathrm{ndA}+\mathrm{bt}^{2}}{2 \mathrm{nA}+2 \mathrm{bt}} .
$$

Position of resultant compression,

$$
\mathrm{z}=\frac{3 \mathrm{kd}-2 \mathrm{t}}{2 \mathrm{kd}-\mathrm{t}} \cdot \frac{\mathrm{t}}{3} \text {. }
$$

Arm of resisting couple,

$$
\mathrm{jd}=\mathrm{d}-\mathrm{z} .
$$

Fiber stresses,

$$
\begin{gathered}
f_{s}=\frac{M}{A j d} . \\
f_{c}=\frac{M k d}{b t\left(k d-\frac{1}{2} t\right) j d}=\frac{f_{s}}{n} \cdot \frac{k}{1-k} .
\end{gathered}
$$

(For approximate results the formulas for rectangular beams may be used.)

- 2 he following formulas take into account the compression in the stem; they are recommended where the flange is small compared with the stem:

Position of neutral axis,

$$
k d=\sqrt{\frac{2 n d A+\left(b-b^{\prime}\right) t^{2}}{b^{\prime}}+\left(\frac{n A+\left(b-b^{\prime}\right) t}{b^{\prime}}\right)^{2}}-\frac{n A+\left(b-b^{\prime}\right) t}{b^{\prime}} .
$$

Position of resultant compression,

$$
z=\frac{\left(k d t^{2}-\frac{2}{3} t^{3}\right) b+\left[(k d-t)^{2}\left(t+\frac{1}{3}(k d-t)\right)\right] b^{\prime}}{t(2 k d-t) b+(k d-t)^{2} b^{\prime}} .
$$

Arm of resisting couple,

$$
\mathrm{jd}=\mathrm{d}-\mathbf{z} \text {. }
$$

Fiber stresses,

$$
\begin{gathered}
f_{s}=\frac{M}{A j d} . \\
f_{c}=\frac{2 M k d}{\left[(2 k d-t) b t+(k d-t)^{2} b^{\prime}\right] j d} .
\end{gathered}
$$


3. Beams Reinforced for Compression.

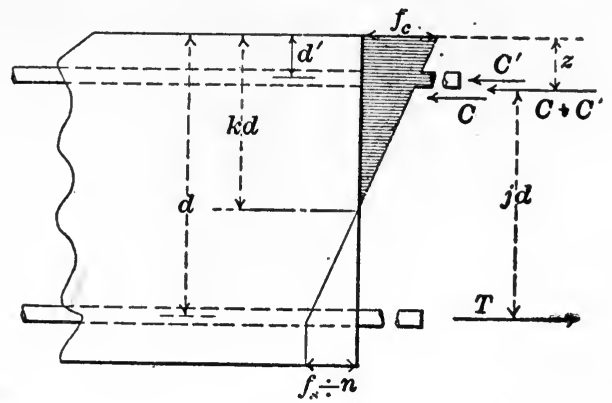

FIG. 4.

Position of neutral axis,

$$
k=\sqrt{2 n\left(p+p^{\prime} \frac{d^{\prime}}{d}\right)+n^{2}\left(p+p^{\prime}\right)^{2}}-n\left(p+p^{\prime}\right) .
$$

Position of resultant compression,

$$
z=\frac{\frac{1}{3} k^{3} d+2 p^{\prime} n d^{\prime}\left(k-\frac{d^{\prime}}{d}\right)}{k^{2}+2 p^{\prime} n\left(k-\frac{d^{\prime}}{d}\right)} .
$$

Arm of resisting couple,

$$
\mathrm{jd}=\mathrm{d}-\mathrm{z} \text {. }
$$

Fiber stresses,

$$
\begin{gathered}
f_{c}=\frac{6 M}{b d^{2}\left[3 k-k^{2}+\frac{6 p^{\prime} n}{k}\left(k-\frac{d^{\prime}}{d}\right)\left(1-\frac{d^{\prime}}{d}\right)\right]} . \\
f_{s}=\frac{M}{p j b d^{2}}=\operatorname{nf}_{c} \frac{1-k}{k} . \\
f_{s}{ }^{\prime}=\operatorname{nf}_{c} \frac{k-\frac{d^{\prime}}{d}}{k} .
\end{gathered}
$$

4. Shear, Bond and Web Reinforcement.

In the following formulas $\Sigma_{0}$ refers only to the bars constituting the tension reinforcement at the section in question and $\mathrm{jd}$ is the lever arm of the resisting couple at the section. 
For rectangular beams,

$$
\begin{gathered}
v=\frac{V}{b j d} . \\
u=\frac{V}{j d . \Sigma_{0}} .
\end{gathered}
$$

[For approximate results $\mathrm{j}$ may be taken at $\frac{7}{8}$.]

The stresses in web reinforcement may be estimated by means of the following formulas:

Vertical web reinforcement,

$$
\mathrm{P}=\frac{\mathrm{Vs}}{\mathrm{jd}} \text {. }
$$

Web reinforcement inclined at $45^{\circ}$ (not bent-up bars).

$$
\mathrm{P}=0.7 \frac{\mathrm{Vs}}{\mathrm{jd}},
$$

in which $\mathrm{P}=$ stress in single reinforcing member, $\mathrm{V}=$ amount of total shear assumed as carried by the reinforcement, and $\mathrm{s}=$ horizontal spacing of the reinforcing members.

The same formulas apply to beams reinforced for compression as regards shear and bond stress for tensile steel.

For T-Beams,

$$
\begin{gathered}
v=\frac{V}{b^{\prime} j d} . \\
u=\frac{V}{j d \cdot \Sigma_{0}} .
\end{gathered}
$$

[For approximate results $\mathrm{j}$ may be taken at $\frac{7}{8}$.]

\section{Columns.}

Total safe load,

$$
P=f_{c}\left(A_{c}+n A_{s}\right)=f_{c} A(1+(n-1) p) .
$$

Unit stresses,

$$
\begin{gathered}
f_{\mathrm{c}}=\frac{\mathrm{P}}{\mathrm{A}(1+(\mathrm{n}-1) \mathrm{p})} . \\
f_{\mathrm{s}}=\mathrm{nf}_{\mathrm{c}} .
\end{gathered}
$$




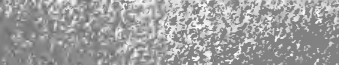

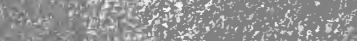

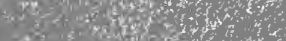

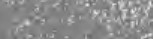

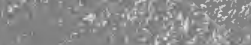

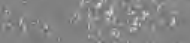

in

$20 \%$

1
1

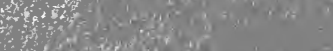

-

. 
THIS BOOK IS DUE ON THE LAST DATE STAMPED BELOW

AN INITIAL FINE OF 25 CENTS WILL BE ASSESSED FOR FAILURE TO RETURN THIS BOOK ON THE DATE DUE. THE PENALTY WILL INCREASE TO 50 CENTS ON THE FOURTH DAY AND TO \$1.00 ON THE SEVENTH DAY OVERDUE.

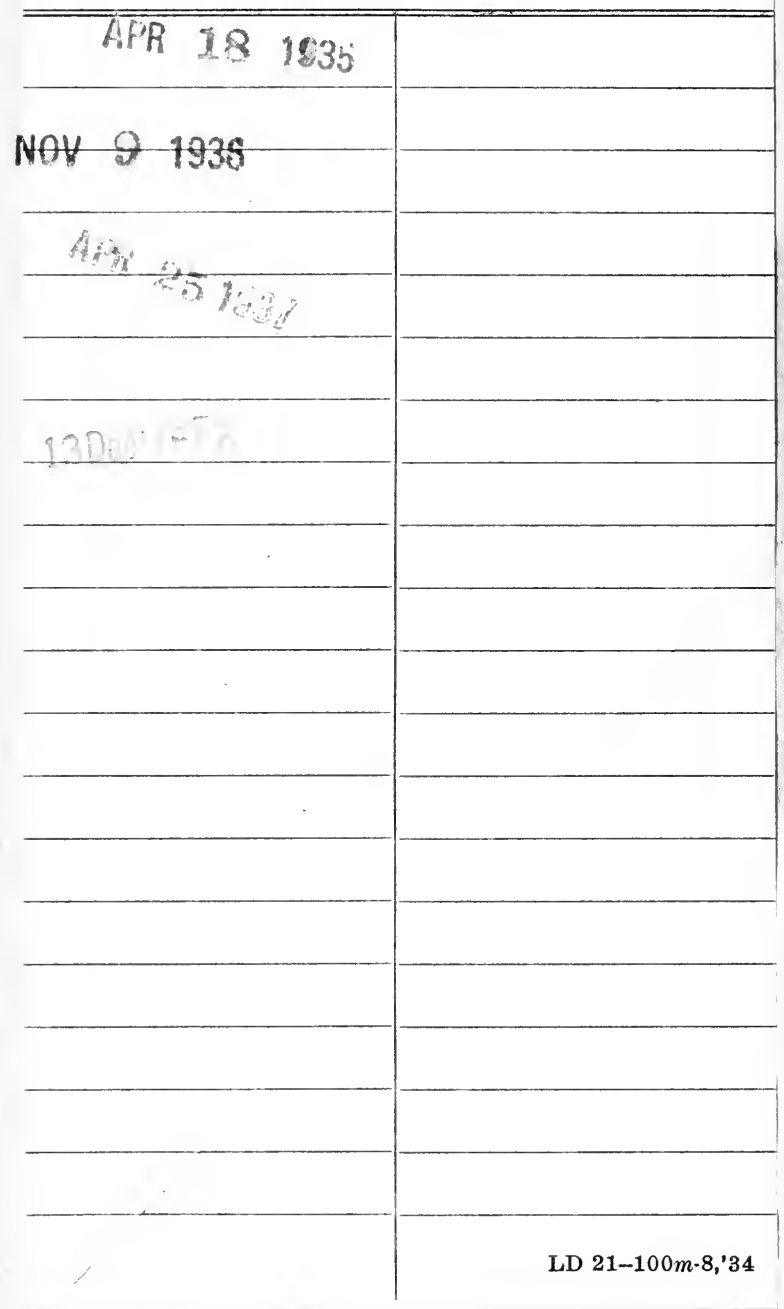


